\title{
Modeling synthetic aperture radar (SAR) scattering from a seasonally varying snow-covered sea ice volume at 5.3 and $9.25 \mathrm{GHz}$
}

\author{
DAVID G. BARBER AND ELLSWORTH F. LEDREW
}

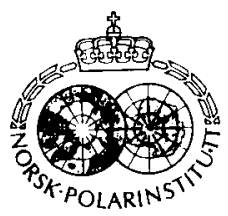

Barber, D. G. \& LeDrew, E. F. 1994: Modeling synthetic aperture radar (SAR) scattering from a seasonally varying snow-covered sea ice volume at 5.3 and $9.25 \mathrm{GHz}$. Polar Research 13. 35-54.

A serics of sensitivity analyses using dielectric, mixture and microwave scattering models is presented. Data from the Seasonal Sea Ice Monitoring and Modeling Site (SIMMS) in 1990 and 1991 are used to initialize the models. The objective of the research is to investigate the role of various geophysical and electrical properties in specifying the total relative scattering cross section $\left(\sigma^{\prime \prime}\right)$ of snow covered first-year sea ice during the spring period.

The seasonal transition period from the Winter SAR scattering season to Early Melt was shown to signal a transition in dielectric properties which caused the snow volume to become a factor in the microwave scattering process. The effect of the thermal insulation of a snow cover on sea ice was shown to be significant for both $\varepsilon^{\prime}$ and $\varepsilon^{\prime \prime}$. Higher atmospheric temperatures caused proportionally greater changes in the dielectric properties of the sea ice at the base of the snow cover. Model $\sigma^{0}$ was computed for a range of sensor, sensor-earth geometry, and geophysical properties. In the Winter season the surface roughness terms $\left(\sigma_{\mathrm{h}}\right.$

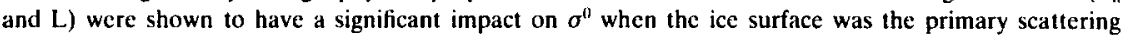
mechanism. Once the snow cover began to warm and water was available in a liquid phase, the ice surface became masked because of the decrease in microwave penetration depths. During this period the water volume variable dominated $\sigma^{0}$, both from its impact on $\sigma_{v}^{0}$, and due to its control over the dielectric mismatch created at the air/snow interface.

D. G. Barber, Department of Geography, University of Manitoba, Winnipeg, MB, R3T 2N2 Canada; E. F. LeDrew, Earth Observations Laboratory, Department of Geography, University of Waterloo, Waterloo, Ontario, Canada.

\section{Introduction}

In this research a series of electromagnetic interaction models are used to elaborate upon the role which geophysical properties play in defining microwave interaction with snow-covered sea ice. We focus on temporal sensitivity analysis, with the important caveat that spatial variation must be ascertained before seasonal evolution of microwave scattering can be explored. Based on the experience gained from SIMMS'90 and SIMMS'91, the sensitivity analyses conducted are considered typical of the SAR scattering seasons (Livingstone et al. 1987): Winter, Early Melt, Melt Onset, and Advanced Melt.

The scattering of microwave energy over sea ice is a function of the dielectric properties, surface roughness, and volume inhomogeneities of the snow and sea ice. The relative scattering cross section $\left(\sigma^{0}\right)$ changes over time and space. Spatial variability is largely a function of the geophysical properties which contribute to the volume dielectrics, or surface roughness of the material. Temporal variability is strongly controlled by the dielectric mismatch across the air-snow and snowice interfaces. The principal variables are the relative phases of water (ice, liquid and vapour), crystal size, brine volume and the vertical and horizontal roughness point estimates of the surface autocorrelation function.

Active microwave remote sensing consists of a sensor which generates and transmits (hence the term active) microwavelength energy towards a scattering surface over a range of incidence angles. This energy is scattered from the volume inhomogeneities and surface roughness characteristics of the earth material. The synthetic aperture radar (SAR) is the most widely used form of active microwave remote sensing. Common frequencies for orbital and aerial SAR occur at the $5.3 \mathrm{GHz}$ ( $\mathrm{C}$ band) and $9.25 \mathrm{GHz}$ ( $\mathrm{X}$ band) 
frequencies. Polarizations on orbital, single frequency SAR sensors are typically $\mathrm{HH}$ or VV. This means that the signal is both transmitted and received with either a horizontal $(\mathrm{HH})$ or vertical (VV) polarization.

The scattering mechanics of a SAR are a function of the sensor configuration, sensor-earth geometry, and dielectric properties of the material. Scattering can be separated into surface and volume components. If there is a strong dielectric mismatch at a particular interface then the surface scattering will dominate. The relative backscattering coefficient $\sigma^{0}$ is a measure of the amount of returned power per unit area, measured at the SAR antenna.

The relative complex dielectric constant (1) is used to express the permittivity $\left(\varepsilon^{\prime}\right)$ and loss $\left(\varepsilon^{\prime \prime}\right)$ of the material relative to the frequency, polarization and incidence angle of the microwave energy.

$$
\varepsilon^{*}=\varepsilon^{\prime}+\mathrm{j} \varepsilon^{\prime \prime}
$$

Roughness can be approximated by the Fraunhaufer Criterion (2). This provides an index of roughness for a given vertical and horizontal dimension as a function of the angle and frequency of the incident microwave energy, following Ulaby et al. (1986).

$$
\sigma_{\mathrm{h}}<\frac{\lambda}{32 \cos \theta}
$$

A powerful tool for understanding the complexities of the microwave scattering process, and thereby constrain SAR algorithm development, is through the use of first order microwave scattering models. The term first order is used because the models are able to handle only bulk volume attributes. The physics of the interactions are usually handled through radiative transfer (Mie or Rayleigh scattering), surface scattering theories (of the Kirchhoff type) and dielectric mixture models, each of which require geophysical variables as inputs.

This is a forward modeling approach, where the physical properties of the snow and sea ice are known, and the electromagnetic (EM) interactions are predicted. The use of forward modeling allows for an improved understanding of the scattering process through an analysis of individual geophysical variable contributions to the magnitude and seasonal evolution of $\sigma^{0}$. Modeling also allows for interpolation of $\sigma^{0}$ within a constrained range of geophysical observations acquired over a space/time continuum. The final attribute of the modeling process is a capability to extrapolate beyond the spatial and temporal sampling boundaries inherent in the surface data collection.

Geophysical properties of the snow and sea ice were collected over a series of spatial and temporal scales during the Seasonal Sea Ice Monitoring and Modeling Site (SIMMS) experiment (Barber et al. 1991; Barber et al. 1992a). These data are used to evaluate the relative sensitivities of various geophysical properties known to affect microwave interaction with the seasonally variable snow-covered sea ice volume. Sensitivity analyses are conducted both for dielectric properties (i.e., dielectric mixture models) and for total relative scattering cross sections $\left(\sigma^{0}\right)$. The objective is to investigate the magnitude and direction of change in the scattering cross sections as the water in liquid phase increases within the snow cover on landfast first-year sea ice.

\section{Methods}

\section{Microwave scattering models}

The microwave scattering models implemented here separate the scattering process into an airsnow interface, a snow volume, a snow-ice interface and an ice volume. Bulk properties are utilized for each interface and volume. The relative complex dielectric constant is computed at each interface and as a bulk property of each volume. Scattering is constrained to surface conditions meeting the assumptions of the Kirchhoff Physical and Geometric Optics models, and to volume scattering conditions meeting the assumptions of a Rayleigh scattering volume (Ulaby et al. 1986). Details of the model can be summarized into the general categories used in computation, namely: dielectric mixture models; surface scattering models; volume scattering models; and model integration.

\section{Dielectric mixture models}

Dielectric properties are important in microwave scattering because they define the electrical conductivity of the material relative to the wavelength and polarization of the incident energy. This 
defines the amount of energy, and its refraction angle, for layers beneath the snow-air interface.

The dielectric constant is expressed as the complex sum of a real and imaginary part (1) where $\mathrm{j}$ is the square root of negative one. Typically, dielectric mixing models are used to predict the complex dielectric constant of a heterogeneous material. A mixture model is required because both snow and sea ice are combinations of water (in liquid, vapour or ice phases), salt (as a solid or more importantly as brine) and air inclusions.

To estimate the dielectric properties of sea ice it is important to consider the relative proportions of brine within the mixture and the proportion of salts within the brine. The salinity of the brine $\left(S_{b}\right)$ is also a function of the ice temperature (T). With increasing negative temperatures the proportion of salts within the brine mixture increases. This can be computed from 3 to 5 following Assur (1960).

$$
\begin{aligned}
\mathrm{S}_{\mathrm{b}} & =1.725-18.756 \mathrm{~T}-0.3964 \mathrm{~T}^{2}, \\
& -8.2 \leq \mathrm{T} \leq-2^{\circ} \mathrm{C} \\
\mathrm{S}_{\mathrm{b}} & =57.041-9.929 \mathrm{~T}-0.16204 \mathrm{~T}^{2} \\
& -0.002396 \mathrm{~T}^{3},-22.9 \leq \mathrm{T} \leq-8.2^{\circ} \mathrm{C} \\
\mathrm{S}_{\mathrm{b}} & =242.94-1.5299 \mathrm{~T}-0.0429 \mathrm{~T}^{2}, \\
& -36.8 \leq \mathrm{T} \leq-22.9^{\circ} \mathrm{C}
\end{aligned}
$$

The brine volume $\left(V_{b}\right)$ is a function of temperature and salinity ( $\mathrm{Si}$ ) and is inversely proportional to the strength of the ice. Brine volume can be computed from salinity and temperature by (6 to 9), following Frankenstein \& Garner (1967).

$$
\begin{aligned}
\mathrm{V}_{\mathrm{b}} & =10^{-3} \mathrm{~S}_{\mathrm{i}}\left(\frac{52.56}{\mathrm{~T}}-2.28\right),-2.06 \\
& \leq \mathrm{T}-0.5^{\circ} \mathrm{C} \\
\mathrm{V}_{\mathrm{b}} & =10^{-3} \mathrm{~S}_{\mathrm{i}}\left(\frac{45.917}{\mathrm{~T}}-0.930\right),-8.2 \\
& \leq \mathrm{T} \leq-2.06^{\circ} \mathrm{C} \\
\mathrm{V}_{\mathrm{b}} & =10^{-3} \mathrm{~S}_{\mathrm{i}}\left(\frac{43.495}{\mathrm{~T}}-1.189\right),-22.9 \\
& \leq \mathrm{T} \leq-8.2^{\circ} \mathrm{C} \\
\mathrm{V}_{\mathrm{b}} & =10^{-3} \mathrm{~S}_{\mathrm{i}}\left(\frac{49.185}{\mathrm{~T}}-0.532\right),-22.9 \\
& \leq \mathrm{T} \leq-0.5^{\circ} \mathrm{C}
\end{aligned}
$$

Where: $V_{b}$ is brine volume in ppt.

$S$ is the ice salinity in ppt.

$\mathrm{T}$ is temperature in ${ }^{\circ} \mathrm{C}$.

To complete the dielectric mixture model of sea ice, a measure of the size, shape and distribution of the brine and air inclusions is required. This is an important concept because of the geometry of the incident radiation. Clearly there is considerable variation in these parameters within a natural ice surface. Most workers have taken a pragmatic approach to the problem, particularly when the dielectric properties will be utilized in a second model (i.e., in microwave surface scattering). A common approach is to utilize linear approximations (10-13) of $\varepsilon^{\prime}$ and $\varepsilon^{\prime \prime}$ based on empirical results of Vant et al. (1978). $\varepsilon^{\prime}=3.05+7.2 \mathrm{~V}_{\mathrm{b}} / 100$,

First-year ice; $4 \mathrm{GHz}$

$\varepsilon^{\prime \prime}=0.024+3.3 \mathrm{~V}_{\mathrm{b}} / 1000$,

First-year ice; $4 \mathrm{GHz}$

$\varepsilon^{\prime}=2.46+22.4 \mathrm{~V}_{\mathrm{b}} / 1000$,

Multiyear ice; $10 \mathrm{GHz}$

$\varepsilon^{\prime \prime}=0.006+10.0 \mathrm{~V}_{\mathrm{b}} / 1000$,

Multiyear ice; $10 \mathrm{GHz}$

The Polder-Van Santen/de Loor model, which assumes spherical inclusions of brine, can be used to compute the dielectric constant of first year sea ice (14) and an approximate form for $\varepsilon^{\prime}$ can be expressed as (15), following Hoekstra \& Cappillino 1971).

$\varepsilon_{\mathrm{si}}=\varepsilon_{\mathrm{i}}+3 \mathrm{~V}_{\mathrm{b}} \varepsilon_{\mathrm{si}} \frac{\left(\varepsilon_{\mathrm{b}}-\varepsilon_{\mathrm{i}}\right)}{\left(2 \varepsilon_{\mathrm{si}}-\varepsilon_{\mathrm{b}}\right)}$

$\varepsilon_{\mathrm{si}}^{\prime} \cong \frac{\varepsilon_{\mathrm{i}}^{\prime}}{\left(1-3 \mathrm{~V}_{\mathrm{b}}\right)}$

Where $\varepsilon_{\mathrm{i}}$ is the relative permittivity of pure ice and $V_{b}$ is the volume fraction of brine.

The dielectric loss of sea ice (16) has been computed based on a similar mixing model to (14) by Hoekstra \& Cappillino (1971).

$\varepsilon_{\mathrm{si}}^{\prime \prime} \cong \mathrm{V}_{\mathrm{b}} \varepsilon_{\mathrm{b}}^{\prime \prime}$

Where $\varepsilon_{\mathrm{b}}^{\prime \prime}$ is the dielectric loss of brine, and $V_{\mathrm{b}}$ is the brine volume.

When considering the dielectric properties of the snow cover on sea ice it is important to consider that the densities of brine and ice are 
different. This means that the brine volume computed from ( 6 to 9 ) must be weighted by the ratio of brine and ice within the snow volume (17 and 18)

$$
\begin{aligned}
& V_{b}=\left\{\frac{V_{h} P_{b}}{\left(1-V_{b}\right) P_{i}+V_{b} P_{b}}\right\}\left\{\frac{P_{s}}{P_{b}}\right\} \\
& V_{i}=\left\{\frac{\left(1-V_{b}\right) P_{i}}{\left(1-V_{b}\right) P_{i}+V_{b} P_{b}}\right\}\left\{\frac{P_{i}}{P_{s}}\right\}
\end{aligned}
$$

Where $P_{i}$ is the density of pure ice, $P_{s}$, and $P_{b}$ are the density of snow and brine.

When free water becomes available within the snow pack the dielectric properties change considerably. The relationships between $\varepsilon^{\prime}$ and $\varepsilon^{\prime \prime}$ for wet and dry snow have been determined empirically. Models for computation of $\varepsilon^{\prime}$ and $\varepsilon^{\prime \prime}$ of wet snow relative to the values for dry snow, have been developed by Tiuri et al. (1984) and are presented in (19 to 22 ).

$$
\begin{aligned}
& \varepsilon_{\mathrm{dry}}^{\prime}=1+1.7 \mathrm{p}_{\mathrm{dry}}+0.7 \mathrm{P}_{\mathrm{dry}}^{2} \\
& \Delta \varepsilon_{\mathrm{wet}}^{\prime}=\varepsilon_{\mathrm{wet}}^{\prime}-\varepsilon_{\mathrm{dry}}^{\prime} \\
& \Delta \varepsilon_{\text {wet }}^{\prime}=\varepsilon_{\mathrm{w}}^{\prime}\left(0.1 \mathrm{~W}_{\mathrm{v}}+0.8 \mathrm{~W}_{\mathrm{v}}+0.8 \mathrm{~W}_{\mathrm{v}}^{2}\right) \\
& \varepsilon_{\mathrm{wet}}^{\prime \prime}=\varepsilon_{\mathrm{w}}^{\prime \prime}\left(0.1 \mathrm{~W}_{\mathrm{v}}+0.8 \mathrm{~W}_{\mathrm{v}}^{2}\right)
\end{aligned}
$$

Where: $\varepsilon^{\prime}$ is the dielectric permittivity $\varepsilon^{\prime \prime}$ is the dielectric loss $W_{v}$ is the volume fraction of water $\Delta$ denotes a change in a particular parameter

Through use of these dielectric mixture models it is possible to compute the penetration depth $(\delta p)$ of various frequencies of electromagnetic energy into a seasonally dynamic snow-covered sea ice volume (23), following Drinkwater (1989).

$\delta_{\mathrm{p}}=\frac{\lambda}{4 \pi}\left\{\left[\left(1+\left(\frac{\varepsilon^{\prime \prime}}{\varepsilon^{\prime}}\right)^{2}\right)^{1 / 2}-1\right] \frac{\varepsilon^{\prime}}{2}\right\}^{-1 / 2}$

Where $\lambda$ is the SAR wavelength in meters, $\varepsilon^{\prime}$ and $\varepsilon^{\prime \prime}$ are the dielectric permittivity and loss given a particular water volume within the snow pack.

\section{Volume scattering models}

In modeling the relative scattering cross section $\left(\sigma^{0}\right)$ from a snow-covered sea ice volume it is important to specify the contribution of volume scattering $\left(\sigma_{v}^{0}\right)$ from the snow cover. A commonly used volume scattering model, uses a Rayleigh cloud analogy radiative transfer equation. This physical/empirical hybrid assumes that the air bubbles are spherical, distributed uniformly throughout the ice volume, and are of equal size. The backscattering coefficient attributable to the volume scattering cross section $\left(\sigma_{\mathrm{v}}^{0}\right)$ is expressed as (24).

$\sigma_{\mathrm{v}}^{0}(\theta)=\frac{\sigma_{\mathrm{v}} \cos \theta}{2 \mathrm{~K}_{\mathrm{c}}}\left(1-\frac{1}{\left(\exp \left(\mathrm{K}_{\mathrm{c}} \mathrm{D} \sec (\theta)\right)\right)^{2}}\right)$

Where the term $\sigma_{v}$ is a volume scattering coefficient based on a presumed dielectric mixing model and the presence of known ice scattering and water scattering radii in an air background dielectric. The average scattering is considered an independent variable which is a function of the average scattering cross section from a particular scattering centre $\left(\sigma_{b}\right)$ where the subscripts $i$ and $s$ refer to ice and snow respectively. The variable $K_{c}$ is defined as (25) and D is the thickness of the scattering volume (i.e., snow thickness).

$\mathrm{K}_{\mathrm{e}}=\frac{1}{\delta_{\mathrm{p}}}$

The number density $(\mathrm{N})$ is multiplied by the scattering contributions from each in specifying the volume scattering coefficient $\left(\sigma_{v}\right)$. Computation of the average volume scattering coefficient (26), the number density (27), and the ice and snow scattering components ( 28 and 29 ) are:

$\sigma_{\mathrm{v}}=\mathrm{N}_{\mathrm{i}} \sigma_{\mathrm{b}_{\mathrm{i}}}+\mathrm{N}_{\mathrm{w}} \sigma_{\mathrm{b}_{\mathrm{w}}}$

$\mathrm{N}=3 \mathrm{v} / 4 \pi \mathrm{r}^{3}$

Where $v$ is the volume fraction of either water or ice in the snow and $r$ is the radius of the average particle size. The contribution of the ice and water as point scatterers is summarized within the volume scattering term approximated from the combination of ice and water radii scattering centres.

$\sigma_{\mathrm{b}}=\frac{64 \pi^{5} \mathrm{r}^{6}}{\lambda_{0}^{4}}|\mathrm{~K}|^{2}$

Where $\mathrm{K}$ is defined as a complex term which relates the dielectric properties of the scattering centre (either snow particle or water particle) within the air background dielectric (29).

$\mathrm{K}=\frac{\left(\varepsilon_{\mathrm{i}}^{\prime}+\mathrm{j} \varepsilon_{\mathrm{i}}^{\prime \prime}\right)-\left(\varepsilon_{\mathrm{A}}^{\prime}+\mathrm{j} \varepsilon_{\mathrm{A}}^{\prime \prime}\right)}{\left(\varepsilon_{\mathrm{i}}^{\prime}+\mathrm{j} \varepsilon_{\mathrm{i}}^{\prime \prime}\right)+2\left(\varepsilon_{\mathrm{A}}^{\prime}+\mathrm{j} \varepsilon_{\mathrm{A}}^{\prime \prime}\right)}$ 
Where $\mathrm{K}$ is computed for either subscript $\mathrm{i}$ (as shown in (29)) or for $w$ when computing $K$ for the water scattering coefficient. The subscript $A$ refers to the complex properties of the air background dielectric.

\section{Surface scattering models}

A series of models have been found to have reasonably precise application in the field of microwave scattering from snow-covered sea ice (Ulaby et al. 1986; Kim et al. 1984; Drinkwater 1989; Livingstone \& Drinkwater 1991). The scattering physics are predicted within the Kirchhoff scattering models. Two approximations to the Kirchhoff Integral are used here. For an exponentially decaying angular dependence, characteristic of a relatively smooth sea ice or snow surface, the Kirchhoff model with a scalar approximation (Physical Optics formulation) is appropriate, following Ulaby et al. (1986). For surfaces displaying a slowing varying angular dependence, characteristic of a relatively rough sea ice or snow surface, the Kirchhoff model with a stationary phase approximation (Geometric Optics formulation) is used, again following Ulaby et al. (1986).

Physical optics formulation. - For smooth undeformed ice surfaces with rms slopes (s) less than 0.25 radians, the surface scattering model proposed by Eom 1982 (31) using an exponential correlation function (following Drinkwater 1989; Kim et al. 1985) provides reasonable agreement with scatterometer results (Kim 1984). The exponential correlation function can be expressed as $(30)$.

$\mathrm{p}(\mathscr{P})=\exp \left(-\frac{\mathscr{P}}{\mathscr{\ell}}\right)$

The Kirchhoff surface scattering model for either snow surface or ice surface scattering can be described as (30)

$$
\begin{aligned}
& \sigma_{\mathrm{S}}^{0}(\theta)=2\left|\Gamma_{\mathrm{HH}}\right|^{2} \cos ^{2} \theta \exp \left(-4 \mathrm{~K}_{0}^{2} \sigma^{2} \cos ^{2} \theta\right) \\
& \cdot \sum_{n=1}^{x} \frac{\left(4 K_{0}^{2} \sigma^{2} \cos ^{2} \theta\right)^{n}}{n !} \cdot \frac{\left(K_{0}^{2} n / 1\right)}{\left(4 K_{0}^{2} \sin ^{2} \theta+n^{2} / 1^{2}\right)^{3 / 2}}
\end{aligned}
$$

Where parameters of the model related to a horizontally incident and reflected field are:
The wavenumber in air, expressed as a function of the wavelength in metres (32).

$\mathrm{K}_{0}=2 \pi / \lambda$

The Fresnel Reflection Coefficient (33) is a measure of the amount of radiation which is reflected at the interface between adjacent mediums. It is computed as a complex ratio of the dielectric properties of the two materials creating the interface (i.e., air-snow or snow-ice).

$\Gamma_{\mathrm{HH}}=\frac{\xi_{2} \times \cos \theta-\xi \cos \theta^{\prime}}{\xi_{2} \times \cos \theta+\xi_{1} \times \cos \theta^{\prime}}$

Where $\xi_{1}$ and $\xi_{2}$ are the complex dielectric constants of the air and snow (34 and 35).

$\xi_{1}=\frac{1}{2 \sqrt{\varepsilon^{\prime}+\varepsilon^{\prime \prime}}}$, for material \#1 (air)

$\xi_{2}=\frac{1}{2 \sqrt{\varepsilon^{\prime}+\varepsilon^{\prime \prime}}}$, for material 2 (snow)

The change in the incidence angle due to the Fresnel Reflection Coefficient is expressed as (36).

$\cos \theta^{\prime}=\sqrt{\left\{1-\left(\frac{\left(\varepsilon_{\mathrm{A}}^{\prime}+\mathrm{j} \varepsilon_{\mathrm{A}}^{\prime \prime}\right)}{\left(\varepsilon_{\mathrm{s}}^{\prime}+\mathrm{j} \varepsilon_{\mathrm{s}}^{\prime \prime}\right)} \times \sin ^{2} \theta\right)\right\}}$

Where the complex quantities with subscripts A and $s$ are for air and snow. With the snow complex dielectric quantities coming from the dielectric mixing formulae described in (19) to (22) above.

In the case of a vertically incident and reflected electromagnetic field the Fresnel reflection coefficient is expressed as (37):

$\Gamma_{\mathrm{W}}=\frac{\xi_{1} \times \cos \theta-\xi_{2} \times \cos \theta^{\prime}}{\xi_{1} \times \cos \theta+\xi_{2} \times \cos \theta^{\prime}}$

The roughness of the snow (or ice) surface can be described as the RMS height, or vertical roughness $\left(\sigma_{\mathrm{h}}\right)$ and the Correlation Length (L), or horizontal roughness. The ratio of the vertical to horizontal roughness components of a randomly rough field provides a measure of the RMS slope. The greater the RMS slope the rougher the surface.

Geometric optics formulation. - For rough ice surfaces with rms slopes greater than 0.25 radians the surface scattering model proposed by Eom 1982 (39), using a Gaussian correlation function (38) is appropriate. The operational assumptions 
which are different than the scalar analytical solution are: $K_{0} s>2$ and $s>1 / 3$ (following Ulaby et al. 1986 and Drinkwater 1989).

$$
\begin{aligned}
& \mathrm{P}(\mathrm{x})=\exp \left(-\mathrm{x}^{2} / \mathrm{I}^{2}\right) \\
& \sigma_{\mathrm{s}}^{0}(\theta)=\frac{\Gamma(0) \exp \left(-\tan ^{2} \theta / 2 \mathrm{~m}^{2}\right)}{2 \mathrm{~m}^{2} \cos ^{4} \theta}
\end{aligned}
$$

Where: $\Gamma(0)=$ The Fresnel reflection coefficient at normal incidence.

$$
\mathrm{m}=\sqrt{ } \overline{2}\left(\frac{\sigma_{\mathrm{h}}}{\mathrm{L}}\right)
$$

The implementation of these two surface scattering models was done using a spreadsheet programming language on a Mackintosh IIci microcomputer. The validity conditions (Table 1) were tested with each computation of the backscattering coefficient and the appropriate model was automatically selected.

\section{Model integration}

The combined model results for a snow and sea ice volume can be expressed as the component due to snow surface scattering ( $\sigma_{s}^{0}$; Physical Optics or Geometric Optics formulation) and that due to snow volume scattering $\left(\sigma_{v}^{0}\right)$. Note that $\sigma_{s}^{0}$ refers to surface scattering for either the snow or sea ice surface. The same notation is used because, under typical conditions, one or the other surface dominates $\sigma^{0}$, not both.

For computation of $\sigma^{0}$, a common approach is to sum the contributions of each scattering medium, weighted by the transmissivity coefficient. This means that the volume scattering term would be weighted by the transmission coefficient across the air-snow interface $\left(\Psi_{\mathrm{as}}\right)$, which is related to the Fresnel Reflection Coefficient according to [40] and the total scattering from a seasonally evolving snow-covered sea ice surface

Table I. Validity conditions for the geometric optics and physical optics approximations to the Kirchhoff surface scattering integral.

\begin{tabular}{cc}
\hline Physical optics model & Geometric optics model \\
\hline$\sqrt{ } 2 \pm \sigma_{\mathrm{h}} / \mathrm{L}<0.25$ & $(2 \mathrm{k} \sigma \cos \theta)^{2}>10$ \\
$\mathrm{~kL}>6$ and $\mathrm{L}^{2}>2.76 \sigma \lambda$
\end{tabular}

Where: $k=2 \pi / 1 ; \quad \sigma_{h}=$ vertical roughness; $\mathbf{L}=$ horizontal roughness or correlation length. would be (41). Under typical seasonal transition conditions the transmissivity across the air-snow interface $\left(\Psi_{\text {as }}\right)$ is sufficiently small that $\Psi_{\text {si }}$ (i.e., snow-ice) is effectively zero, meaning that the contribution of the ice surface scattering $\sigma_{\mathrm{s}}^{0}$ to $\sigma^{0}$, can be ignored.

$\Psi_{\text {as }}=\left(1-\left|\Gamma_{\mathrm{HH}}\right|\right)$

$\sigma_{\text {total }}^{0}(\theta)=\sigma_{\text {ss }}^{0}+\Psi_{\text {as }}^{2}(\theta)^{*} \sigma_{\text {sv }}^{0}\left(\theta^{\prime}\right)$

Where $\sigma_{\mathrm{ss}}^{0}$ and $\sigma_{\mathrm{sv}}^{0}$ refer to the scattering contributions from the snow surface and snow volume.

\section{Analysis design}

\section{Modeling microwave scattering}

A series of sensitivity analyses are conducted to elaborate upon the effect of 'Dielectric Properties', 'Geophysical Properties', and 'Seasonal Evolution' of the snow-covered sea ice, on microwave scattering.

Dielectric properties. - Dielectric properties are assessed by using the dielectric mixture models described above. The relative effects of $\varepsilon^{\prime}$ and $\varepsilon^{\prime \prime}$ are assessed for a typical range and magnitude of the geophysical properties which give rise to changes in the snow and sea ice geophysical properties. The dielectric models are initialized with geophysical variables measured during SIMMS'90 and SIMMS'91. The dielectric properties of sea ice and of the snow cover are important in specifying the total relative scattering cross section from this surface. Winter conditions are driven primarily by sea ice dielectrics and the seasonal evolution by the snow volume dielectrics.

Geophysical properties. - Geophysical properties are assessed by conducting two sets of sensitivity analyses, designed to determine the relative significance of particular geophysical properties within the Winter season and within the transitional seasons of Early Melt, Melt Onset, and Advanced Melt. These sensitivity analyses are used to evaluate a particular geophysical variable range while holding all other model parameters constant.

The Winter and seasonal transition sensitivity analyses are conducted at 5.3 and $9.25 \mathrm{GHz}$ frequencies at $\mathrm{HH}$ polarization. These frequencies were selected because $5.3 \mathrm{GHz}$ is available from 
the Earth Resource Satellite (ERS-1) and $9.25 \mathrm{GHz}$ is available on the Sea Ice and Terrain Assessment Radar (STAR-2). The frequencies are evaluated over a $10^{\circ}$ to $80^{\circ}$ incidence angle range, at $2.5^{\circ}$ increments, using geophysical data acquired during SIMMS'90 and SIMMS'91.

Two groups (5.3 and $9.25 \mathrm{GHz}$ ) are computed, each with 5 sets of 7 trials (Tables 2 and 3). Each set consists of the analysis of one parameter, tested at five levels, while the other concomitant variables are held constant. The sensitivity analyses are considered valid for typical Winter season conditions and over the range, Melt Onset to Advance Melt. Winter is required as a tie point from which to address the seasonal evolution of $\sigma^{0}$. The physical properties evaluated in the Winter season sensitivity trials are limited to RMS Height and Correlation Length because of their significant effect on microwave scattering.

The sensor, sensor-earth geometry, and geophysical properties used in the seasonal sensitivity analyses include: Microwave Frequency (Fi), Polarization (Pol), Water Volume of the snow
$\left(W_{v}\right)$, Snow Density $(\rho s)$, RMS height $\left(\sigma_{\mathrm{h}}\right)$, Correlation Length (L), Snow Depth $\left(D_{s}\right)$, and the radius of ice crystals in the snow $\left(R_{i}\right)$ and water inclusions within the snow $\left(R_{w}\right)$. The initial conditions and the range of variables tested within each set are described in Table 2 and Table 3.

When interpreting the range and magnitude of $\sigma^{0}$ it is important to note that the two surface scattering models have been implemented so that the parameters being tested in the model automatically determine which model is used. Since the Geometric and the Physical Optics models are approximations of the Kirchhoff Integral there will be imprecisions within the range of parameters where the validity conditions flip from one model to the other. The validity conditions used here are expressed in Table 1.

Seasonal Evolution. - The seasonal evolution of $\sigma^{0}$ was modeled using data from SIMMS'91 over the period Julian day 138 to 163 . Variables used in the modeling were extracted as averages from the snow pit samples acquired from all first year

Table 2. Sensitivity initialization parameters used in modeling trials of a combined snow and sea ice microwave scattering condition.

\begin{tabular}{|c|c|c|c|c|c|c|c|c|}
\hline $\begin{array}{l}\mathrm{F}_{\mathrm{i}} \\
\mathrm{GHz}\end{array}$ & Pol & $\begin{array}{l}W_{v} \\
\% / 100\end{array}$ & $\begin{array}{l}\rho_{\mathrm{s}} \\
\mathrm{kg} \cdot \mathrm{m}^{-3}\end{array}$ & $\begin{array}{l}\sigma_{\mathrm{h}} \\
\text { metres }\end{array}$ & $\begin{array}{l}\mathrm{L} \\
\text { metres }\end{array}$ & $\begin{array}{l}\mathrm{D}_{\mathrm{s}} \\
\text { metres }\end{array}$ & $\begin{array}{l}\mathbf{R}_{\mathrm{i}} \\
\text { metres }\end{array}$ & $\begin{array}{l}\mathbf{R}_{w} \\
\text { metres }\end{array}$ \\
\hline 5.3 & $\mathrm{HH}$ & Variable & 300 & 0.01 & 0.08 & 0.3 & 0.001 & 0.000025 \\
\hline 5.3 & $\mathrm{HH}$ & 0.05 & Variable & 0.01 & 0.08 & 0.3 & 0.001 & 0.000025 \\
\hline 5.3 & $\mathrm{HH}$ & 0.05 & 300 & Variable & 0.08 & 0.3 & 0.001 & 0.000025 \\
\hline 5.3 & $\mathrm{HH}$ & 0.05 & 300 & 0.01 & Variable & 0.3 & 0.001 & 0.000025 \\
\hline 5.3 & $\mathrm{HH}$ & 0.05 & 300 & 0.01 & 0.08 & Variable & 0.001 & 0.000025 \\
\hline 5.3 & $\mathrm{HH}$ & 0.05 & 300 & 0.01 & 0.08 & 0.3 & Variable & 0.000025 \\
\hline 5.3 & $\mathrm{HH}$ & 0.05 & 300 & 0.01 & 0.08 & 0.3 & 0.001 & Variable \\
\hline 9.25 & $\mathbf{H H}$ & Variable & 300 & 0.01 & 0.08 & 0.3 & 0.001 & 0.000025 \\
\hline 9.25 & HH & 0.05 & Variable & 0.01 & 0.08 & 0.3 & 0.001 & 0.000025 \\
\hline 9.25 & $\mathrm{HH}$ & 0.05 & 300 & Variable & 0.08 & 0.3 & 0.001 & 0.000025 \\
\hline 9.25 & $\mathrm{HH}$ & 0.05 & 300 & 0.01 & Variable & 0.3 & 0.001 & 0.000025 \\
\hline 9.25 & $\mathrm{HH}$ & 0.05 & 300 & 0.01 & 0.08 & Variable & 0.001 & 0.000025 \\
\hline 9.25 & $\mathrm{HH}$ & 0.05 & 300 & 0.01 & 0.08 & 0.3 & Variable & 0.000025 \\
\hline 9.25 & HH & 0.05 & 300 & 0.01 & 0.08 & 0.3 & 0.001 & Variable \\
\hline
\end{tabular}

Table 3. Variable conditions tested in the sensitivity analyses (Table 2). The term "variable" in Table 2 is represented by the range of conditions specified by the 5 sets presented.

\begin{tabular}{llllllll}
\hline Set & $\begin{array}{l}\mathrm{W}_{\mathrm{v}} \\
\% / 100\end{array}$ & $\begin{array}{l}\rho_{\mathrm{s}} \\
\mathrm{gm} \cdot \mathrm{cm}^{-3}\end{array}$ & $\begin{array}{l}\sigma_{\mathrm{h}} \\
\text { metres }\end{array}$ & $\begin{array}{l}\mathrm{L} \\
\text { metres }\end{array}$ & $\begin{array}{l}\mathrm{D}_{\mathrm{s}} \\
\text { metres }\end{array}$ & $\begin{array}{l}\mathbf{R}_{\mathrm{i}} \\
\text { metres }\end{array}$ & $\begin{array}{l}\mathbf{R}_{\mathrm{w}} \\
\text { metres }\end{array}$ \\
\hline 1 & 0.001 & 0.1 & 0.001 & 0.06 & 0.1 & 0.0001 & 0.000005 \\
2 & 0.0325 & 0.2 & 0.005 & 0.105 & 0.325 & 0.001325 & 0.000129 \\
3 & 0.055 & 0.3 & 0.009 & 0.150 & 0.55 & 0.00255 & 0.000252 \\
4 & 0.075 & 0.4 & 0.013 & 0.195 & 0.75 & 0.003775 & 0.000376 \\
5 & 0.01 & 0.5 & 0.017 & 0.24 & 1.0 & 0.005 & 0.0005 \\
\hline
\end{tabular}


ice sites. The variables $W_{v}, \rho_{s}$, and $R_{i}$ were extracted as a time sequence, with interpolation across adjacent points to account for missing data.

Water volumes were highly variable over the diurnal cycle. Daily averages were computed from data collected between the hours of approximately 1000 and $1800 \mathrm{hrs}$ (local time). The water volumes were interpolated between days where Wv measurements were missing. After Julian day 156 , the snow pack began to drain as the transition between pendular and funicular regimes was realized. To approximate the bulk snow pack water properties the water volume was extrapolated, based on the trend observed between Julian days 149 and 156 , to day 163.

The variables $\sigma_{h}, L, D_{s}$ and $R_{w}$ were fixed at the average value observed between Julian days 138 and 163 . Frequency was evaluated at 5.3 and $9.25 \mathrm{GHz}$ with horizontal send and receive $(\mathrm{HH})$ polarization. Incidence angles were computed for $20^{\circ}, 30^{\circ}$ and $40^{\circ}$. These approximate the frequency and polarization of many operational SAR sensors and the orbital incidence angle ranges which are, or will be, available on ERS-1 and RADARSAT.

The seasonal evolution of $\sigma^{0}$ illustrates the magnitude of $\sigma^{0}$ which can be expected from a seasonal evolution of the geophysical properties which give rise to microwave scattering. The values presented are daily averages, and as such, are considered appropriate only as an indicator of seasonal evolution. Diurnal variation in $W_{v}$ and $\mathbf{R}_{\mathbf{i}}$ within the snow can cause dramatic shifts in the microwave scattering response from the snowcovered sea ice surface (Barber et al. 1992b).

\section{Results and discussion}

\section{Dielectric properties}

In the context of microwave scattering, winter sea ice can be considered as a three component medium: ice crystals, air pockets, and brine. Each component has a very different complex dielectric constant at microwave frequencies and exists in different characteristic sizes, shapes, volumes and surface distributions (Livingstone 1989). Since the scale sizes of the constituents $(\sim \mathrm{mm}$ to $\sim \mathrm{cm})$ are within the range of wavelengths found at microwave frequencies, we can expect characteristic signatures based on the scattering from the constituent combinations. In general the average relative complex dielectric constant of sea ice is a function of these constituent parts, relative to the look direction of the electric field (Ulaby et al. 1986). The brine inclusions exercise the strongest control on the average complex dielectric constant of sea ice because the permittivity is much higher $\left(\varepsilon^{\prime}=\sim 70\right)$ than that of pure ice $\left(\varepsilon^{\prime}=3.15\right.$; Johannsson \& Askne 1987; Winebrenner 1989).

The relative volume of brine in sea ice has been shown to be a function of temperature and salinity, and is inversely proportional to the strength of the ice. Figs. 1 and 3 show the effect of varying temperatures and salinities on the permittivity and loss of first-year and multi-year sea ice at 4 and $10 \mathrm{GHz}$ frequencies. These graphs are computed from empirical dielectric models (10 to 12), following Vant et al. (1978).

In general, the permittivity of sea ice decreases with decreasing temperature and increases with increasing salinity (Figs. 1 and 2). The permittivity of multi-year ice would be lower than that of firstyear ice at the same frequency. The dielectric loss $\left(\varepsilon^{\prime \prime}\right)$ of sea ice increases with increasing salinity and temperature (Fig. 3). A dielectrically "lossy" material is one with a high $\varepsilon^{\prime \prime}$. Higher values of $\varepsilon^{\prime \prime}$ result in lower microwave penetration depths into the ice surface and therefore a larger contribution of surface scattering to $\sigma^{\prime \prime}$. Multi-year ice has a lower $\varepsilon^{\prime \prime}$ value than first-year ice because of the lower salinity and density of the upper layer.

In the context of microwave scattering, the snow cover on sea ice can be considered as a combination of snow crystals and water inclusions within an air background. Snow cover on sea ice is different than snow found on terrestrial surfaces in two aspects, each of which are important to SAR scattering from sea ice. First, when new ice forms, a hoar layer develops. This hoar frost is highly saline and forms a snow cover in the fall without mass inputs from blowing or falling snow (Drinkwater \& Crocker 1988). Since this hoar layer $(\mathrm{Hd})$ is high in salinity and water content it affects both thermal and vapour transfers between the ice and atmosphere. Second, as snowfall is added over this hoar layer there is a transfer of brine from the hoar layer into the overlaying snow through both mechanical mixing and as a result of capillary suction from the snow cover. Typical salinities of snow-covered first-year ice show that the brine concentrations are highest at the bottom of the snowpack and decrease towards the surface. For thin snow covers on newly formed 


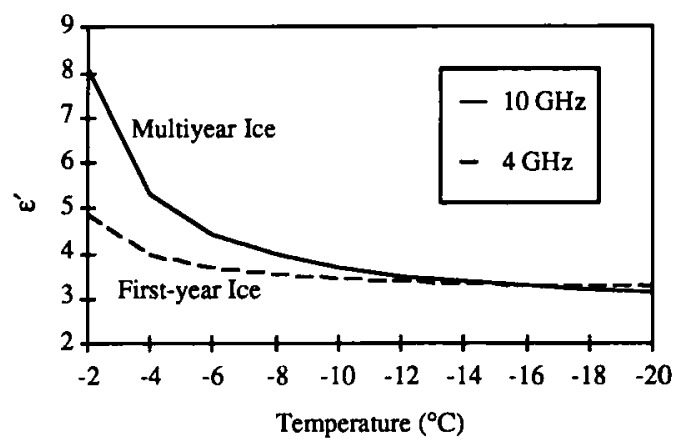

Fig. 1. Permittivity as a function of ice type, frequency and temperature.

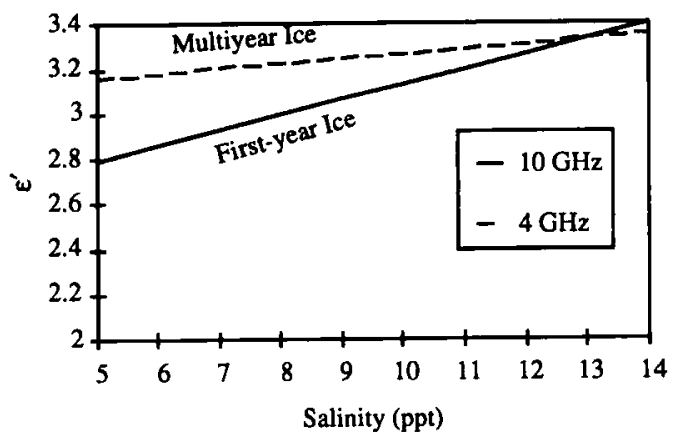

Fig. 2. Permittivity as a function of ice type, frequency and salinity.

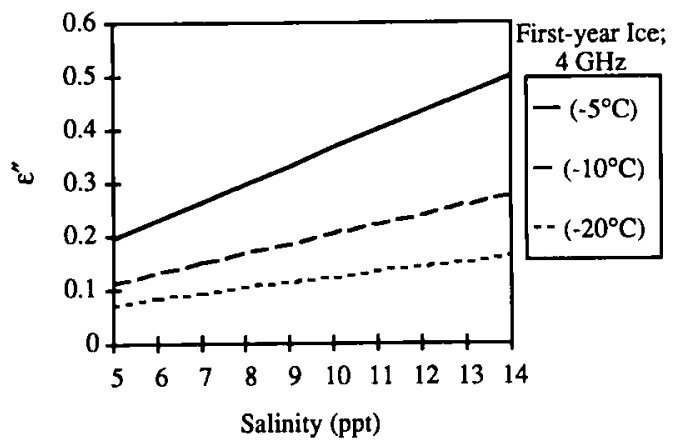

Fig. 3. Dielectric loss as a function of temperature and salinity.

ice, salinities can be in excess of $40 \mathrm{ppt}$ and for thicker snow covers over thicker ice, salinities have been found in excess of $20 \mathrm{ppt}$ (Crocker 1984).

The winter snow cover on sea ice is a three component medium, containing various pro- portions of air, brine and ice. As with any heterogeneous material, the average relative complex dielectric constant is due to the dielectric constants of each of the constituent parts. The dielectric permittivity of dry snow $\left(\varepsilon^{\prime}\right)$ is approximately 1.18 at a density of $0.1 \mathrm{gm} \cdot \mathrm{cm}^{-3}$ and increases to 2.03 at a density of $0.5 \mathrm{gm} \cdot \mathrm{cm}^{-3}$. When the wavelengths are larger than the snow crystals (which is generally the case) $\varepsilon^{\prime}$ is independent of frequency. Dielectric loss $\left(\varepsilon^{\prime \prime}\right)$ of dry snow is frequency dependent and has been measured between a range of $2 \times 10^{-4}$ to $1 \times 10^{-3}$ for frequencies from 5 to $40 \mathrm{GHz}$ (Matzler 1987; Colbeck 1981).

The seasonal transition snow cover consists of much different relative proportions of the three water phases. The increase in the amount of water, in a liquid phase plays an important role in specifying the permittivity and loss of the snow cover. The effect of water volumes between 0.1 and 10 percent are shown to be density and frequency dependent. Permittivity of wet snow increases both with increasing water content and with increasing snow density (Fig. 4). The dielectric loss of a wet snow cover is density independent and water volume dependent (Fig. 5). As water volume increases between 0.1 and 10 percent $\varepsilon^{\prime \prime}$ increases from 0.004 to 0.667 . Note that the $\varepsilon^{\prime \prime}$ of dry snow is approximately 0.0008 (Tiuri et al. 1984). A 5.3 GHz frequency was used in computing $\varepsilon^{\prime}$ and $\varepsilon^{\prime \prime}$ in Figs. 4 and 5.

When the electromagnetic frequencies are considered, both $\varepsilon^{\prime}$ and $\varepsilon^{\prime \prime}$ are shown to be frequency and water volume dependent. Permittivity increases with decreasing frequency or conversely, longer wavelengths result in larger permittivity (Fig. 6). The relationship between $\varepsilon^{\prime \prime}$ and frequency illustrates an important point regarding the Debye relaxation spectrum for water. As the water volume increases there is an increase in $\varepsilon^{\prime \prime}$ (Fig. 7). The rate of increase appears to be variable amongst the 4.0 to $12.0 \mathrm{GHz}$ frequencies with maximum $\varepsilon^{\prime \prime}$ occurring at about the $10 \mathrm{GHz}$ frequency (Fig. 7). A more detailed view of this relationship shows that $\varepsilon^{\prime \prime}$ peaks at about the $10 \mathrm{GHz}$ frequency (Fig. 8). This corresponds to the relaxation frequency of water based on the Debye Spectrum (Matzler 1987).

The final condition, of importance in dielectric modeling, is the effect of snow cover on the relationship between atmospheric and snow-ice interface temperatures. From snow depth, ice 


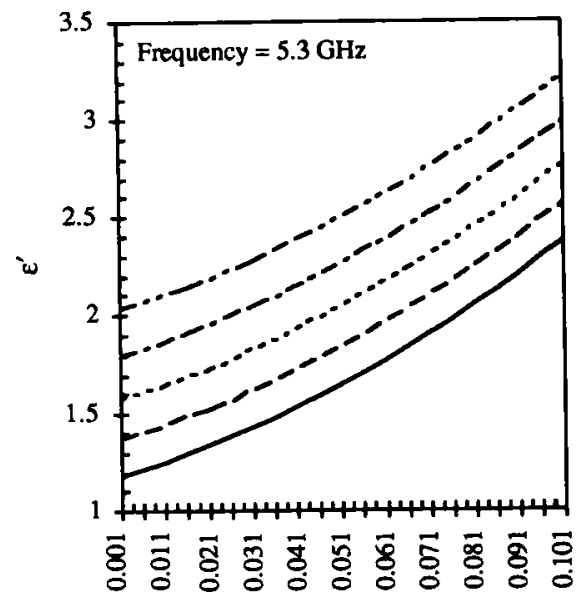

Water Volume $(\% / 100)$

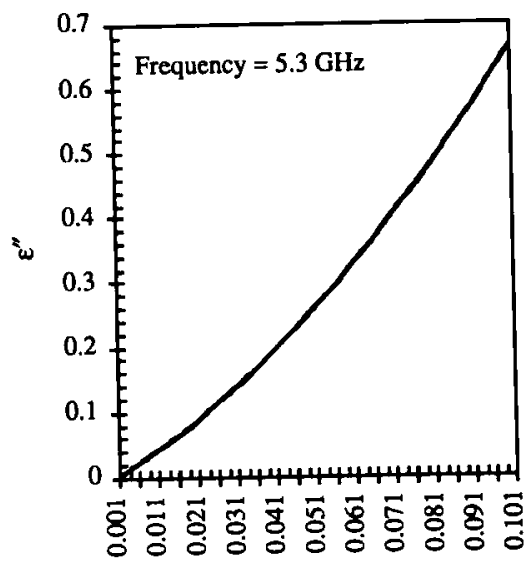

Water Volume $(\% / 100)$

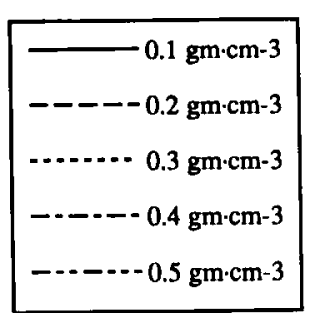

Fig. 4. Dielectric permittivity $\left(\varepsilon^{\prime}\right)$ as a function of water volume and snow density. Models used in computing these results are described in equations (19) to (22).
Fig. 5. Dielectric loss $\left(\varepsilon^{\prime \prime}\right)$ as a function of water volume and snow density. Models used in computing these results are described in equations (19) to (22).

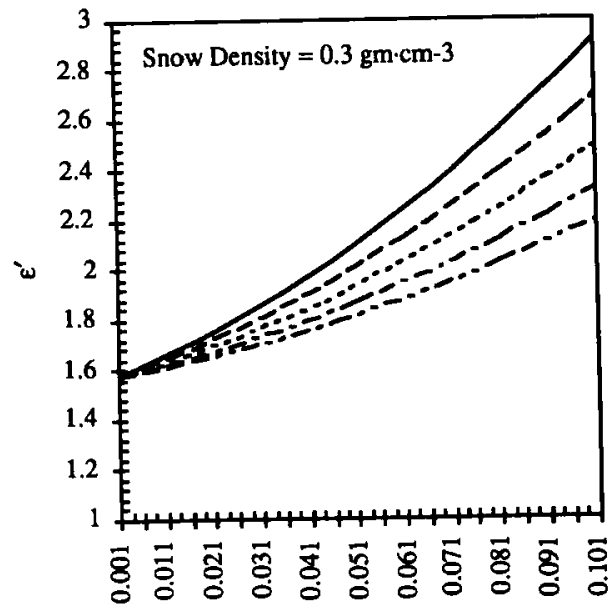

Water Volume $(\% / 100)$

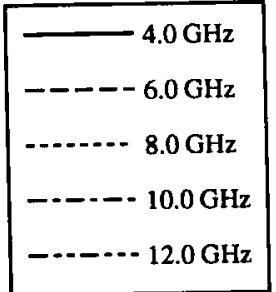

Fig. 6. Dielectric permittivity $\left(\epsilon^{\prime}\right)$ as a function of water volume and microwave frequency. Models used in computing these results are described in equations (19) to (22). 


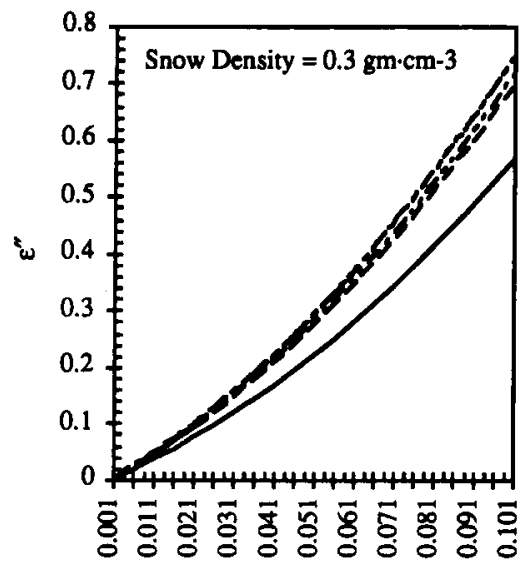

Water Volume $(\% / 100)$

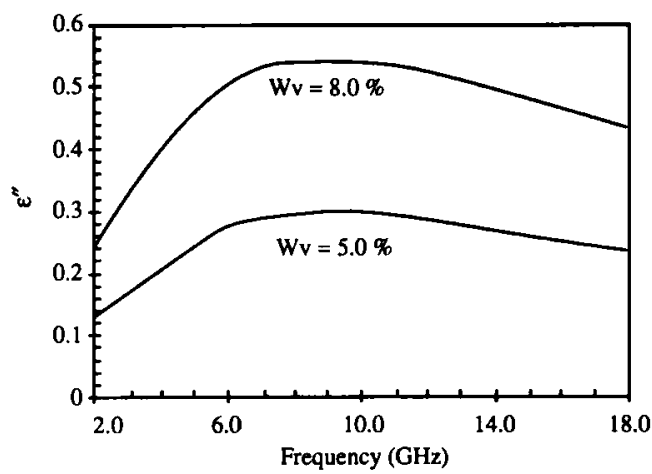

Fig. 8. Diclectric loss $\left(\varepsilon^{\prime \prime}\right)$ for 5.0 and $8.0 \%$ water by volume. Peak $\varepsilon^{\prime \prime}$ occurs at approximately $10 \mathrm{GHz}$ frequency for both water volume conditions.

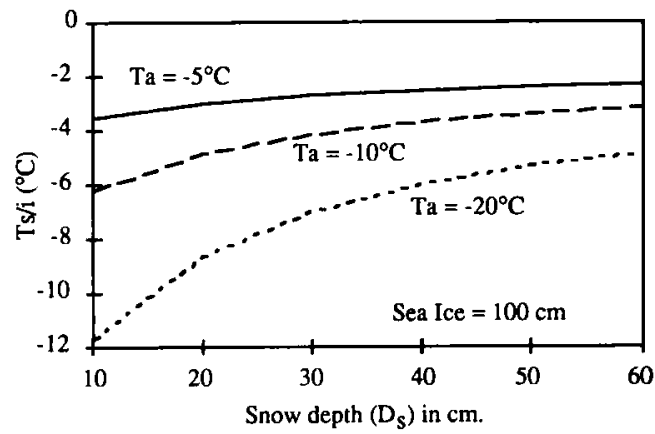

Fig. 9. Temperature at the ice surface as a function of snow depth and air temperature.
Fig. 7. Dielectric loss $\left(\varepsilon^{\prime \prime}\right)$ as a function of water volume and microwave frequency. Models used in computing these results are described in equations (19) to (22).

thickness, and atmospheric temperature, ice surface temperatures can be estimated using a one dimensional thermodynamic model (Nakawo \& Sinha 1981). The relationship between various snow depths over a $1 \mathrm{~m}$ thick first-year ice surface is presented in Fig. 9. It is apparent from this figure that a snow cover can make a considerable difference on the snow-ice interface temperature $\left(\mathrm{T}_{\mathrm{s} / \mathrm{i}}\right)$ depending on the snow depth $\left(\mathrm{S}_{\mathrm{d}}\right)$ and ambient temperatures $\left(T_{a}\right)$.

The snow cover effects the ice surface temperature, which effects the brine volume of sea ice, which in-turn effects the dielectric constant. The volume of brine can then be used in computation of the average complex dielectric constant of sea ice under winter conditions (Fig. 10). When the effect of snow cover on the surface

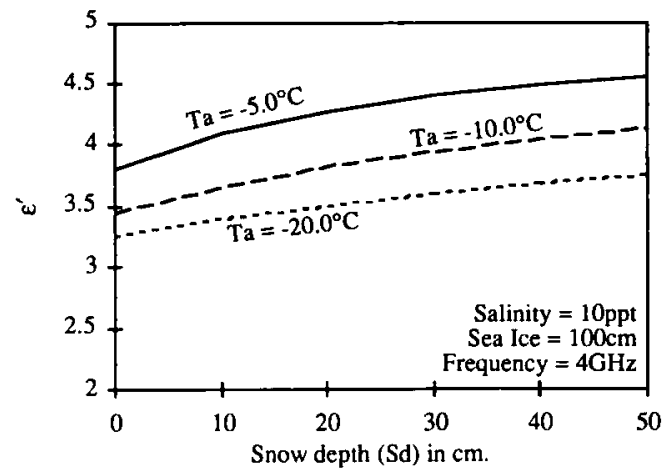

Fig. 10. Change in permittivity $\left(\varepsilon^{\prime}\right)$ of the dielectric constant as a function of snow cover on a $100 \mathrm{~cm}$ thick ice sheet. 
temperature is considered, it is possible to compute $\varepsilon^{\prime}$ as a function of snow depth, ice thickness and microwave frequency using equations (10 to 13) (Vant et al. 1978).

The slope of each line in Fig. 10 provides a measure of the sensitivity of snow cover on the dielectric properties of the sea ice surface. As expected, the higher the atmospheric temperature, the larger the magnitude change in $\varepsilon^{\prime}$. The largest increase is between no snow cover and $10 \mathrm{~cm}$. This is because the thermal insulation of even a thin snow cover is significant.

The relationship between $\varepsilon^{\prime \prime}$ and snow cover is plotted in Fig. 11. The same general relationship as $\varepsilon^{\prime}$ is evident. There is a larger increase between no snow cover and a $10 \mathrm{~cm}$ cover. There is also a larger difference between $-10^{\circ} \mathrm{C}$ and $-5^{\circ} \mathrm{C}$, relative to $-10^{\circ} \mathrm{C}$ and $-20^{\circ} \mathrm{C}$, atmospheric temperatures.

In summary, both $\varepsilon^{\prime}$ and $\varepsilon^{\prime \prime}$ decrease as frequency increases. Although this is a complex relationship, the major factor appears to be the interrelationships between brine conductivity and the relaxation mechanism of water with increasing temperature. Although the volume of brine is much smaller than the volume of ice there is still a disproportionate influence because of the dielectric mismatch between brine (70-j20) and ice (3.15-j0.01); Vant et al. 1978; Tiuri et al. 1984).

Snow cover provides the most interesting changes in $\sigma^{0}$ when free water becomes available in the snow pack. As the water content increases the penetration depth of microwaves into the snow pack decreases. By linking the microwave frequency $(\lambda)$, the permittivity of dry snow (19), the change in $\varepsilon^{\prime}$ due to wetness $\left(\Delta \varepsilon^{\prime}\right.$ wet; $\left.(21)\right)$, and the dielectric loss of wet snow (22), a general model (23) can be used to compute penetration depth $(\delta p)$.

Fig. 12 shows the impact of very small quantities of water on the penetration depths at a variety of snow densities. As the penetration depth decreases, the average scattering from the snowcovered sea ice contains an increasing contribution from the snow volume and snow surface geometry. Density plays only a minor role in specifying the penetration depths at $5.3 \mathrm{GHz}$ into the snow cover. Fig. 13 shows the effect of varying frequency, at a constant density for $\delta \mathrm{p}$. Frequency appears to contribute somewhat to the variability in microwave penetration depths.

Note that within the range 0.001 to 0.01 water by volume $(0.1$ to $1.0 \% \mathrm{Wv})$, the penetration depths at all snow densities between 0.1 and $0.5 \mathrm{gm} \cdot \mathrm{cm}^{-3}$ dropped from $2.493 \mathrm{~m}$ to $0.239 \mathrm{~m}$. This constitutes an order of magnitude drop in penetration depths, over a range of snow wetness conditions which can occur very rapidly during the seasonal transition from Winter to Melt Onset. These penetration curves represent a minimum estimate since the scattering losses are assumed negligible in this simple model. This is an important caveat since at such high water volumes there will undoubtedly be development of scattering mechanisms within the snow (i.e., ice lenses, layers, polycrystalline snow aggregates, etc.).

The dramatic impact of small quantities of water, in liquid phase, reflect the conditions examined with the dielectric mixture models. The relaxation spectrum of water results in a minimum penetration depth at about the $10 \mathrm{GHz}$ region (Fig. 14). When the snow wetness reaches about 1 percent water by volume, the snow cover dominates the scattering return since typical snow thicknesses exceed the $24 \mathrm{~cm}$ estimated by modeling $\delta \mathrm{p}$. This means that the focus for SAR scattering over the transitional periods from Winter to Summer should focus principally on the snow volume dielectric and scattering mechanisms.

\section{Geophysical properties}

In the Winter Season the vertical component of the surface roughness $\left(\sigma_{h}\right)$ is shown to have considerable influence on the scattering return at both $\mathrm{C}$ band $(5.3 \mathrm{GHz})$ and $X$ band $(9.25 \mathrm{GHz})$ frequencies (Fig. 15). The models were initialized with a correlation height of $0.08 \mathrm{~m}$, an ice salinity of $7 \mathrm{ppt}$, an ice surface temperature of $-20^{\circ} \mathrm{C}$, and dielectric properties specified by $(15)$ and (16). Given these conditions the RMS roughness heights of $0.001,0.005,0.009,0.013$, and 0.017 illustrate increasing scales of ice surface roughness.

The slow angular fall off in $\sigma^{0}$ at the RMS height of 0.001 is typical of the Kirchhoff Physical Optics model for scattering from a loss less first year ice surface. The large increase in scattering between the 0.001 and 0.009 level illustrates the importance of surface roughness to SAR scattering. This range represents an approximate $12 \mathrm{~dB}$ change in scattering, attributable to a minor change in surface roughness from $1 \mathrm{~mm}$ to $5 \mathrm{~mm}$ RMS height. Equivalent changes in surface roughness between $0.005 \mathrm{~m}$ to 0.13 metres show 


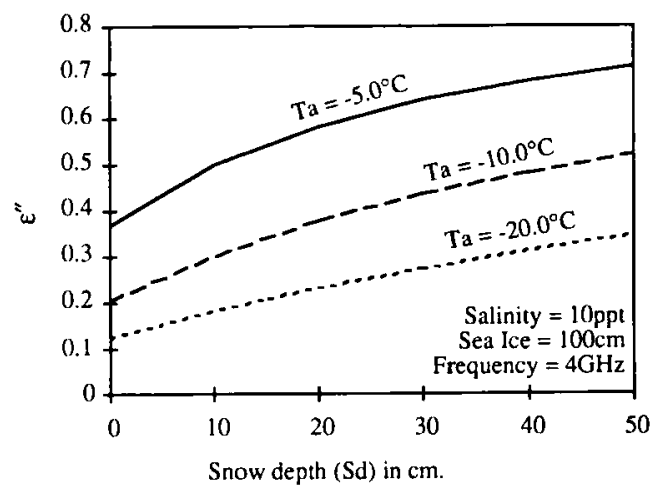

Fig. 11. Change in dielectric loss $\left(\varepsilon^{\prime \prime}\right)$ as a function of snow cover on a $100 \mathrm{~cm}$ thick ice sheet.

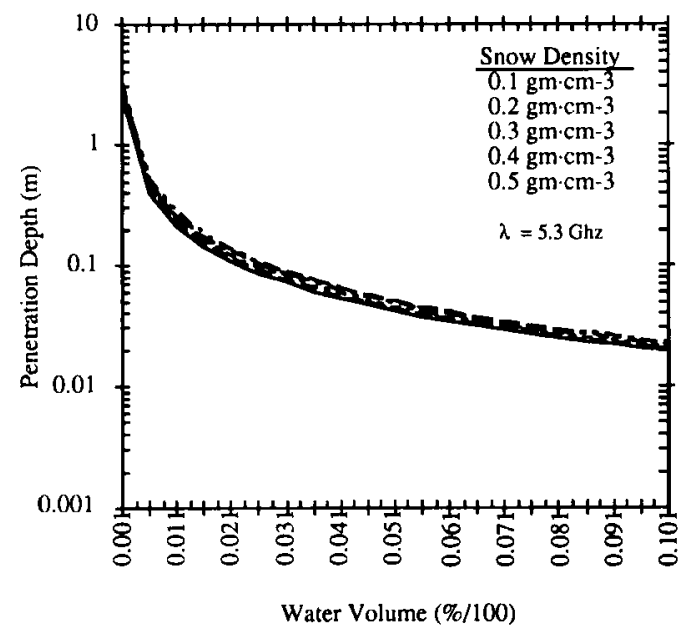

Fig. I2. Relationship between microwave penetration depth $(\delta \mathrm{p})$ and volume fraction of water $\left(\mathrm{W}_{\mathrm{v}}\right)$ at snow densities ranging from 0.1 to $0.5 \mathrm{gm} \cdot \mathrm{cm}^{-3}$ at a frequency of $5.3 \mathrm{GHz}$.

that roughness becomes less important as the RMS height increases (Fig. 15).

The distinct difference in the $0.017 \mathrm{~m}$ RMS height curve is a function of both the mechanics of the modeling process and significance sensorsurface roughness geometry. At an RMS height of $0.017 \mathrm{~m}$ the Geometric Optics model is more appropriate for specifying the incidence angle dependence of $\sigma^{0}$. The dramatic shape difference is a result of the fact that the Physical and Geometric Optics approximations are not a continuum, but rather two distinct approximations to particular geometrical conditions. The

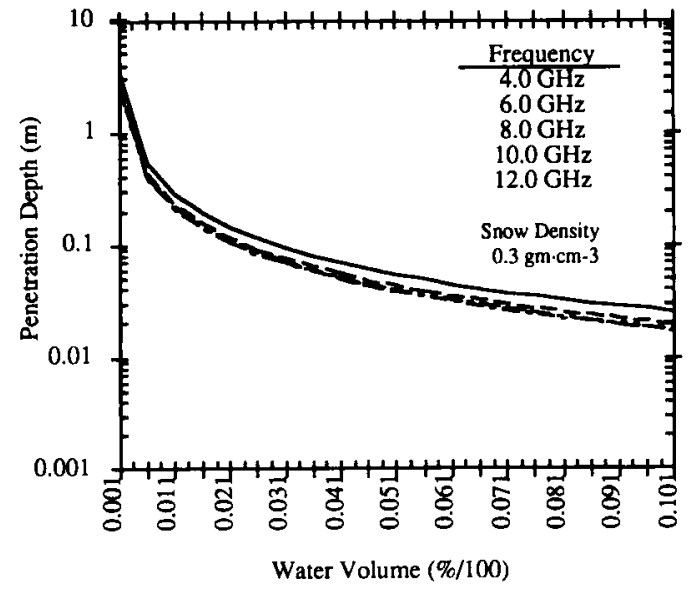

Fig. 13. Relationship between microwave penetration depth $(\delta \mathrm{p})$ and volume fraction of water $(\mathrm{Wv})$ at frequencies ranging from 4 to $12 \mathrm{GHz}$ and a snow density of $0.3 \mathrm{gm} \cdot \mathrm{cm}^{-3}$.

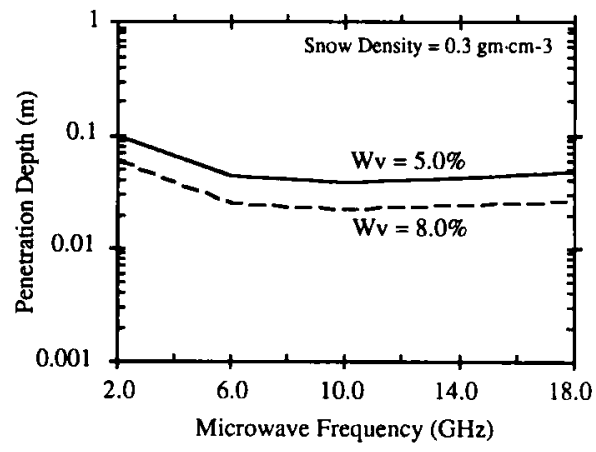

Fig. 14. Penetration depth $(\delta \mathrm{p})$ for 5.0 and $8.0 \%$ water by volume. Minimum $\delta \mathrm{p}$ occurs at approximately $10 \mathrm{GHz}$ frequency for both water volume conditions.

shape of the curve largely reflects the geometry of the model (i.e., slowly varying angular dependence to surface roughness using a Gaussian correlation function). The rapid decrease after about $40^{\circ}$ also illustrates that the roughness between 10 and $40^{\circ}$ is detected by the sensor but at larger incidence angles, the angular dependence is such that the energy is scattered coherently in the specular direction.

The horizontal component of the surface roughness (L) is shown to have a minor (compared with the RMS height) influence on the scattering return, during winter conditions, at both 5.3 and 


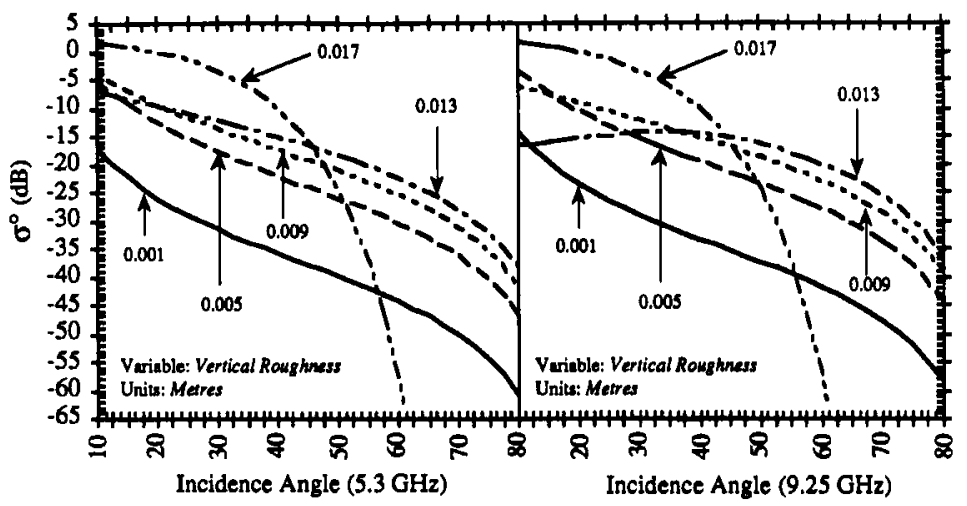

Fig. 15. Sensitivities of the ice surface RMS height $\left(\sigma_{h}\right)$ variable at 5.3 and $9.25 \mathrm{GHz}$ frequencies over the incidence angle range 10 to $80 \mathrm{deg}$ rees.
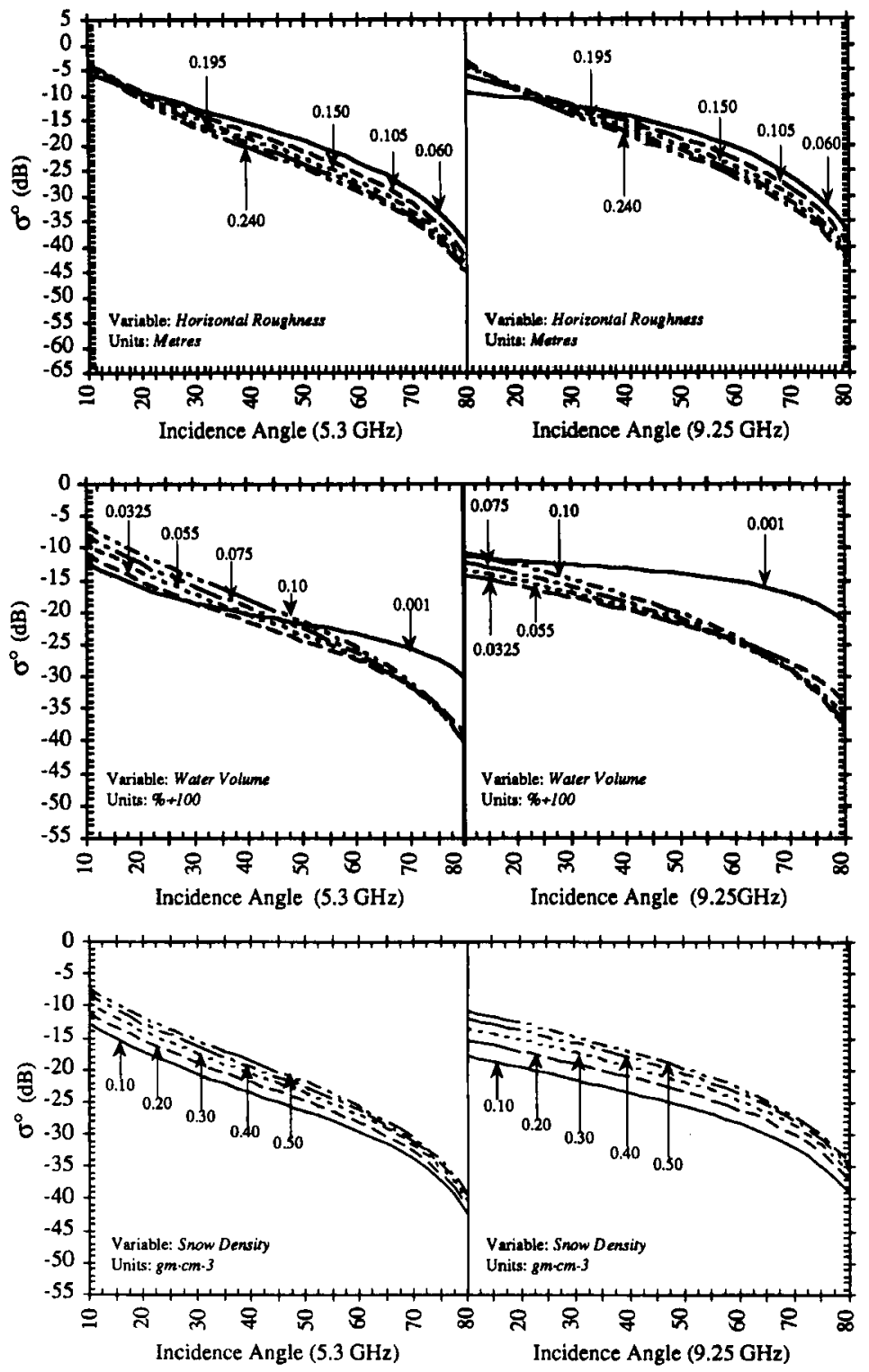

Fig. 16. Sensitivities of the ice surface roughness correlation length (L) variable at 5.3 and $9.25 \mathrm{GHz}$ frequencies over the incidence angle range 10 to 80 degrees.

Fig. 17. Sensitivities of the water volume $\left(W_{v}\right)$ variable at 5.3 and $9.25 \mathrm{GHz}$ frequencies over the incidence angle range 10 to 80 degrees. Initialization conditions of concomitant variables are specified in Table 2.

Fig. 18. Sensitivities of the snow density $\left(\rho_{\mathrm{s}}\right)$ variable at 5.3 and 9.25 GHz frequencies over the incidence angle range 10 to 80 degrees. Initialization conditions of concomitant variables are specified in Table 2. 
9.25 GHz frequencies (Fig. 16). The models were initialized with an RMS height of $0.01 \mathrm{~m}$, an ice salinity of $7 \mathrm{ppt}$, an ice surface temperature of $-20^{\circ} \mathrm{C}$, and dielectric properties specified by (15) and (16). Given these conditions the RMS roughness heights of $0.60,0.105,0.150,0.195$ and $0.240 \mathrm{~m}$ depict decreasing scales of ice surface roughness (Fig. 16).

The slow angular decrease in $\sigma^{0}$ at all levels of the correlation length variable indicates that the Physical Optics conditions were met with all the parameters of this sensitivity analysis. The general decrease in the scattering returns through the range of correlation lengths indicates that between $6 \mathrm{~cm}$ and $24 \mathrm{~cm}$, given that all the other parameters are held constant, we can expect a maximum difference in $\sigma^{0}$ of about $5 \mathrm{~dB}$. The inflection points, where the relative scattering reverses, at about $15^{\circ}$ and $25^{\circ}$ at 5.3 and $9.25 \mathrm{GHz}$ respectively, illustrate the relative nature of the term 'roughness'. At the shallower incidence angles the effect of surface roughness can actually reverse the magnitude of $\sigma^{0}$, relative to other incidence angles (note $0.06 \mathrm{~m}$ curve in Fig. 16) curve at $9.25 \mathrm{GHz}$ on either side of the $25^{\circ}$ incidence angle.

The RMS height $\left(\sigma_{\mathrm{h}}\right)$ and correlation length (L) of a Winter season ice cover are typical of the surface scattering one can expect from first year ice. The magnitude of $\sigma^{0}$ provides a measure of the scattering for a first year ice surface roughness using a range of values typical of the SIMMS study area for winter conditions (i.e., typically January to April).

In the transitional seasons of Early Melt, Melt Onset and Advance Melt Water Volume $\left(W_{v}\right)$ within the snow pack is shown to have a significant impact on the total relative scattering cross section $\left(\sigma^{0}\right)$. At $5.3 \mathrm{GHz}$ an increase in water volume $\left(W_{y}\right)$ from 0.1 to 10 percent can create a maximum difference in scattering of about $7 \mathrm{~dB}$ (Fig. 17). Note that the relative effect of $W_{v}$ is highly skewed to the smaller values (i.e., 0.001). This means that small water volumes are more important than larger ones and that an effect can occur with water volumes as low as $0.1 \%$ water by volume. At $9.25 \mathrm{GHz}$ a W $\mathrm{v}$ of $0.1 \%$ produces a much higher $\sigma^{0}$ because the shorter wavelengths are more sensitive to the presence of small water volumes (Fig. 17). We could expect a maximum difference of $11 \mathrm{~dB}$ between 0.1 and $10.0 \%$ water by volume at $9.25 \mathrm{GHz}$.

It is interesting to note that at $5.3 \mathrm{GHz} \mathrm{a} \mathrm{W}_{\mathrm{v}}$ of
$0.1 \%$ would provide a lower scattering return than at a $W_{v}$ of $3 \%$ for incident angles between 10 and $30 \%$. After this incidence angle there is a transition period where the low $W_{v}$ increases the $\sigma^{0}$ relative to all the higher water volumes. This is a function of the relative contributions of surface and volume scattering to the specification of $\sigma^{0}$. As the incidence angles increase, the transmission coefficient $\left(\psi^{2}\right)$ decreases. This means that the volume term becomes less important, relative to the surface term (41), at larger incidence angles. Since the larger water volumes have smaller volume scattering terms, the combined scattering continues to decrease at the same rate as at smaller incidence angles (Fig. 17).

This effect is evident in the shorter wavelength $(9.25 \mathrm{GHz})$ model, but the impact of a small $\mathrm{W}_{\mathrm{v}}$ is exacerbated because the shorter wavelength is more sensitive to the surface roughness parameters (Table 2) used in the initialization of this sensitivity trial. Also note that the $\sigma^{0}$ drops when $\mathrm{W}_{\mathrm{v}}$ is increased from 0.001 to $0.0325(\% / 100)$. With further increases in $\mathrm{W}_{\mathrm{v}}$ the $\sigma^{0}$ increases, within the incidence angle ranges $10^{\circ}$ to $60^{\circ}$. Beyond this incidence angle range the relationship reverts to a decrease in $\sigma^{0}$ with increasing $W_{v}$. This complex relationship is a result of the dual role $\mathrm{W}_{\mathrm{v}}$ plays in increasing both $\sigma_{\mathrm{v}}^{0}$ and $\sigma_{\mathrm{s}}^{0}$ The former being virtually angular independent and the later highly angular dependent (Fig. 17).

Snow density $\left(\rho_{\mathrm{s}}\right)$ also plays an important role in determining the microwave scattering at $\mathrm{C}$ and $\mathrm{X}$ bands (Fig. 18). At $5.3 \mathrm{GHz}$ an increase in $\rho_{\mathrm{s}}$ from 0.1 to $0.5 \mathrm{gm} \cdot \mathrm{cm}^{-3}$ can create a maximum difference in scattering of about $5 \mathrm{~dB}$. Note that the relative effect of $\rho_{\mathrm{s}}$ is approximately a linear increase in $\sigma^{0}$ over all incidence angles, as the snow density increases. This increase is due to larger values of both the $\sigma_{\mathrm{s}}^{0}$ and $\sigma_{\mathrm{v}}^{0}$ components of $\sigma^{0}$. The $\sigma_{\mathrm{s}}^{0}$ is increased because of the effect of snow density on the dielectric properties of the snow volume. The $\sigma_{v}^{0}$ is increased because of the enhance scattering from the volume inhomogeneities and the increased dielectric properties attributable to the $\rho_{\mathrm{s}}$ variable (Fig. 18).

At $9.25 \mathrm{GHz}$ an increase in snow density $\left(\rho_{\mathrm{s}}\right)$ from 0.1 to $0.5 \mathrm{gm} \cdot \mathrm{cm}^{-3}$ can create a maximum difference in scattering of about $8 \mathrm{~dB}$. As with the $5.3 \mathrm{GHz}$ case, an increase in $\sigma^{0}$ occurs as the density increases. The larger range of $\sigma^{0}$ is due to the larger volume scattering term at 9.25 relative to $5.3 \mathrm{GHz}$ (Fig. 18). The smaller angular drop off at the $9.25 \mathrm{GHz}$ frequency is a function 

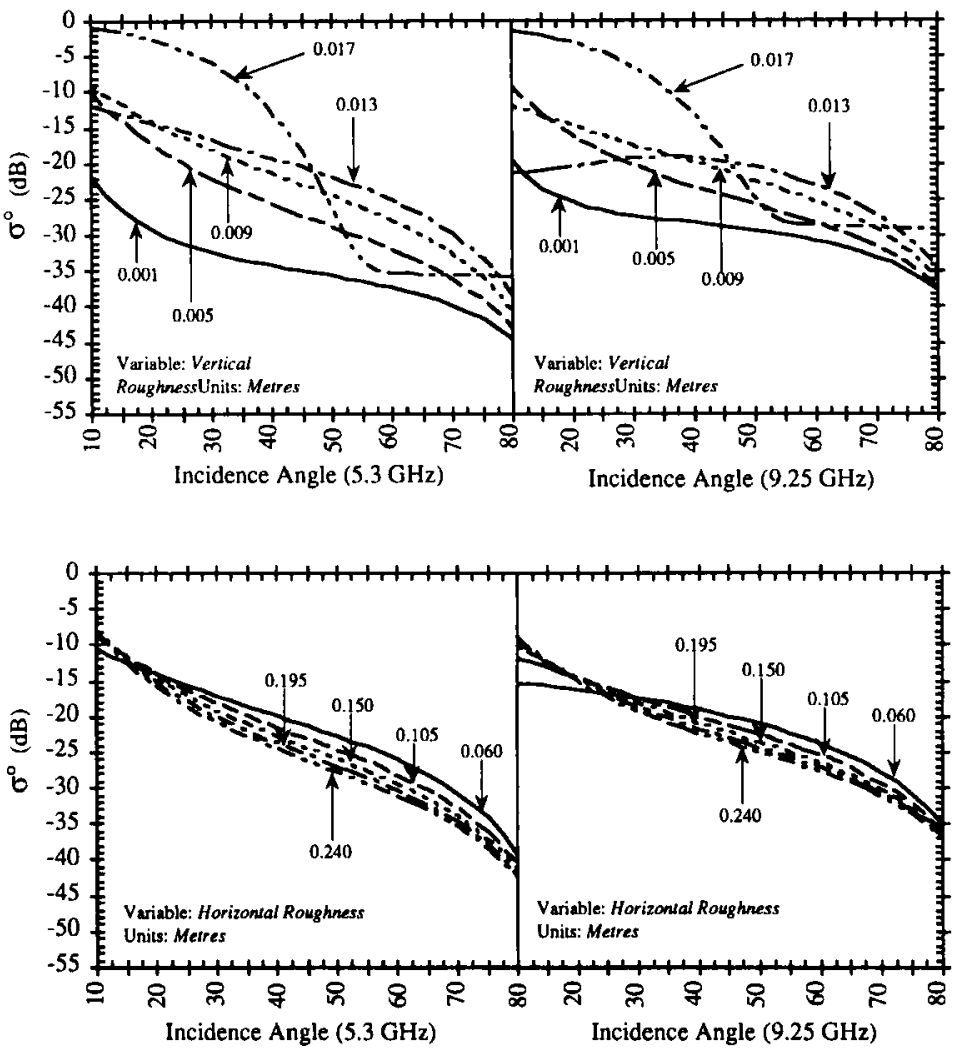

Fig. 19. Sensitivities of the snow surface RMS height $\left(\sigma_{h}\right)$ variable at 5.3 and $9.25 \mathrm{GHz}$ frequencies over the incidence angle range 10 to 80 degrees. Initialization conditions of concomitant variables are specified in Table 2.

Fig. 20. Sensitivities of the snow surface correlation length $(L)$ variable at 5.3 and $9.25 \mathrm{GHz}$ frequencies over the incidence angle range 10 to 80 degrees. Initialization conditions of concomitant variables are specified in Table 2 .

Fig. 21. Sensitivities of the snow depth (D) variable at 5.3 and $9.25 \mathrm{GHz}$ frequencies over the incidence angle range 10 to 20 degrees. Initialization conditions of concomitant variables are specified in Table 2 .

of the surface roughness term in specification of $\sigma^{0}$ (i.e., the surface appears rougher to the $\mathrm{X}$ band radar).

Vertical roughness or RMS height $\left(\sigma_{h}\right)$ is an important parameter in specifying the relative scattering return from the snow-covered sea ice (Fig. 19). As a general principal, the presence of water volume in the snow pack means that surface roughness of the snow becomes important. When the snow pack is dry, the Fresnel Reflection Coefficient $(\Gamma)$ is near zero (both at the air/snow and snow/ice interfaces), which means that most of the incident energy is transmitted across these interfaces and interacts either with the volume inhomogeneities or with the surface roughness of the sea ice. 
At $5.3 \mathrm{GHz}$ an increase in $\sigma_{\mathrm{h}}$ from $1 \mathrm{~mm}$ to $17 \mathrm{~mm}$ can create a difference in $\sigma^{0}$ of more than $30 \mathrm{~dB}$ (Fig. 19). Note that the relative effect of $\sigma_{\mathrm{h}}$ follows the same basic pattern for roughness heights of from 0.001 to $0.013 \mathrm{~m}$. The $0.017 \mathrm{~m}$ height reflects both an artifact of the modeling process and a transition period where roughness dramatically impacts the scattering process. For the conditions tested, the $0.017 \mathrm{~m}$ parameters were most appropriately modeled with the Geometric Optics formulation (39). This model uses a Gaussian correlation function which results in a slow angular drop in $\sigma^{0}$ up to an incidence angle where the surface no longer appears rough (Fig. 19). The inflection point in the curve at $\sigma^{0}=$ $-35 \mathrm{~dB}$ at an angle of $57^{\circ}$ is caused when $\sigma^{0}$ reaches the volume scattering floor, specified by the initialization parameters used in these trials.

At $9.25 \mathrm{GHz}$ an increase in RMS height $\left(\sigma_{\mathrm{h}}\right)$ from 0.001 to $0.017 \mathrm{~m}$ can create a maximum difference in scattering of about $25 \mathrm{~dB}$ (Fig. 19). As with the $5.3 \mathrm{GHz}$ case, an increase in $\sigma^{0}$ occurs as $\sigma_{\mathrm{h}}$ increases. Note that an increase in $\sigma^{0}$ occurs for the $0.013 \mathrm{~m}$ trial from 10 to $40^{\circ}$ incidence angles (Fig. 19). This appears to be a continuation of the trend evident at the 10 to $15^{\circ}$ incidence angles at $5.3 \mathrm{GHz}$ where the rougher surface actually tend to show smaller $\sigma^{0}$ values.

Correlation length (L) or the horizontal component of the surface roughness is important in surface scattering because it is a component of the roughness statistics. At $5.3 \mathrm{GHz}$ an increase in $\mathrm{L}$ from 6 to $24 \mathrm{~cm}$ can create a maximum difference in scattering of about $6 \mathrm{~dB}$ (Fig. 20). As the correlation length increases $\sigma^{0}$ decreases. This is because the roughness, observed by the microwave energy, decreases with increasing correlation length and increasing incidence angle. Note that the relative effect of the correlation length is approximately a curvalinear decrease in $\sigma^{0}$ over all incidence angles greater than $20^{\circ}$. At $9.25 \mathrm{GHz}$ an increase in correlation length from 6 to $24 \mathrm{~cm}$ can create a maximum difference in scattering of about $4 \mathrm{~dB}$ (Fig. 20). Note that the inflection point, where the shorter correlation lengths create a relatively lower $\sigma^{0}$ occur at larger incidence angles (i.e., $15^{\circ}$ at $5.3 \mathrm{GHz}$ and $30^{\circ}$ at $9.25 \mathrm{GHz}$ ). This is a function of the roughness relative to the sensor-sea ice geometry.

When RMS height and correlation length of the snow surface are both considered (Figs. 19 and 20 ), the most significant aspect about roughness is that the relative magnitude of $\sigma^{0}$ is a function of the roughness, relative to the incidence angle and frequency of the radiation. The reversal of $\sigma^{0}$ at incidence angles below $30^{\circ}$ in the $9.25 \mathrm{GHz}$ case appears to be consistent between both the RMS height and the correlation length. This is because the vertical and horizontal components of roughness are a tradeoff. It is perhaps simpler to consider RMS slopes (" $m$ " in equation (39)) as an index of roughness. It is also important to note that RMS heights $\left(\sigma_{\mathrm{h}}\right)$ of snow and sea ice can be obtained with reasonable precision. Correlation lengths (L) are much less precise because of difficulties in specifying a spatial interval over which to compute the summary statistic.

The snow depth $\left(D_{s}\right)$ variable would be a valuable parameter to invert from microwave scattering because of its influence on energy and radiation balance parameters. At $5.3 \mathrm{GHz}$ there is no significant separation of the five depth trials. This is because the slope of the scattering angular dependence is specified by the snow surface roughness and the volume scattering term is driven by the size distribution of volume inhomogeneities within the snow. Snow depth is sufficiently less important so that no detectable difference is observed (Fig. 21). At $9.25 \mathrm{GHz}$ the same conclusions may be drawn, with the notable exception that the slope of the curves is decreased over the $10^{\circ}$ to $60^{\circ}$ incidence range because of the impact of surface roughness at the shorter wavelength (Fig. 21).

Further examination of this relationship shows that at lower values of $W_{v}$ the separation of $D_{s}$ increases, albeit marginally (Fig. 22). Of note is that the separation of snow depths is enhanced when two frequencies are compared. A maximum separation of $7 \mathrm{~dB}$ occurs between 5.3 and $9.25 \mathrm{GHz}$ for both $0.1 \mathrm{~m}$ and $1.0 \mathrm{~m}$ snow depths at a water volume of $1 \%$ (Fig. 22). Separation of snow depth classes may be possible using water volume in combination with multifrequency data.

The snow crystal radius $\left(R_{i}\right)$ variable shows considerable variation over the range of conditions tested. At $5.3 \mathrm{GHz}$ the difference in scattering increases from a minimum of $2 \mathrm{~dB}$ at $10^{\circ}$ to a maximum of $18 \mathrm{~dB}$ at $80^{\circ}$ incidence (Fig. 23). The increase in $\sigma^{0}$ with increasing snow crystal radius is caused by an increase in the scattering cross section of the ice crystal $\left(\sigma_{\mathrm{bi}}\right)$ which creates an increase in the volume scattering coefficient $\left(\sigma_{v}^{0}\right)$.

At $9.25 \mathrm{GHz}$ the snow crystal radius enhances the difference in scattering amongst the five trials 


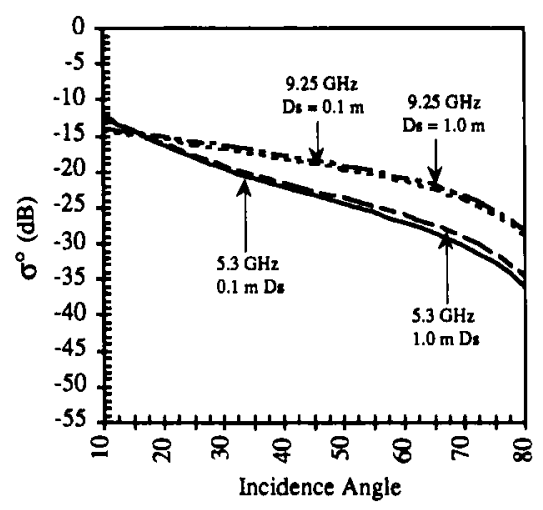

Fig. 22. Relationship between snow depth $\left(D_{s}\right)$ at 0.1 and $1.0 \mathrm{~m}$, and frequency at 5.3 and $9.25 \mathrm{GHz}$ over the incidence angle range 10 to 80 degrees. Initialization conditions of concomitant variables are consistent with those in Fig. 21 (see Table 2) with the exception of $W_{v}$ which was set to 0.01 . is a result of the general increase in the volume scattering at all crystal radii, from the shorter $9.25 \mathrm{GHz}$ radiation. The scattering cross section of the ice crystals $\left(\sigma_{\mathrm{bi}}\right)$ is an order of magnitude larger for the 9.25 relative to the $5.3 \mathrm{GHz}$ frequency.

Water inclusion radius $\left(R_{w}\right)$ shows no discernible variation in $\sigma^{0}$ over the two frequency groups tested. The difference in the slope of the 5.3 versus $9.25 \mathrm{GHz}$ groups is a function of the surface roughness concomitant variable (Fig. 24). The water inclusion radius $\left(R_{w}\right)$ and the snow crystal radius $\left(R_{i}\right)$ are used in specifying the volume scattering coefficient $\left(\sigma_{v} ;(25)\right)$ which is then used in computation of the volume scattering cross section $\left(\sigma_{v}^{0}(24)\right)$. Differences in the size of the inclusions appear to have no impact on the scattering trials computed here. This results from
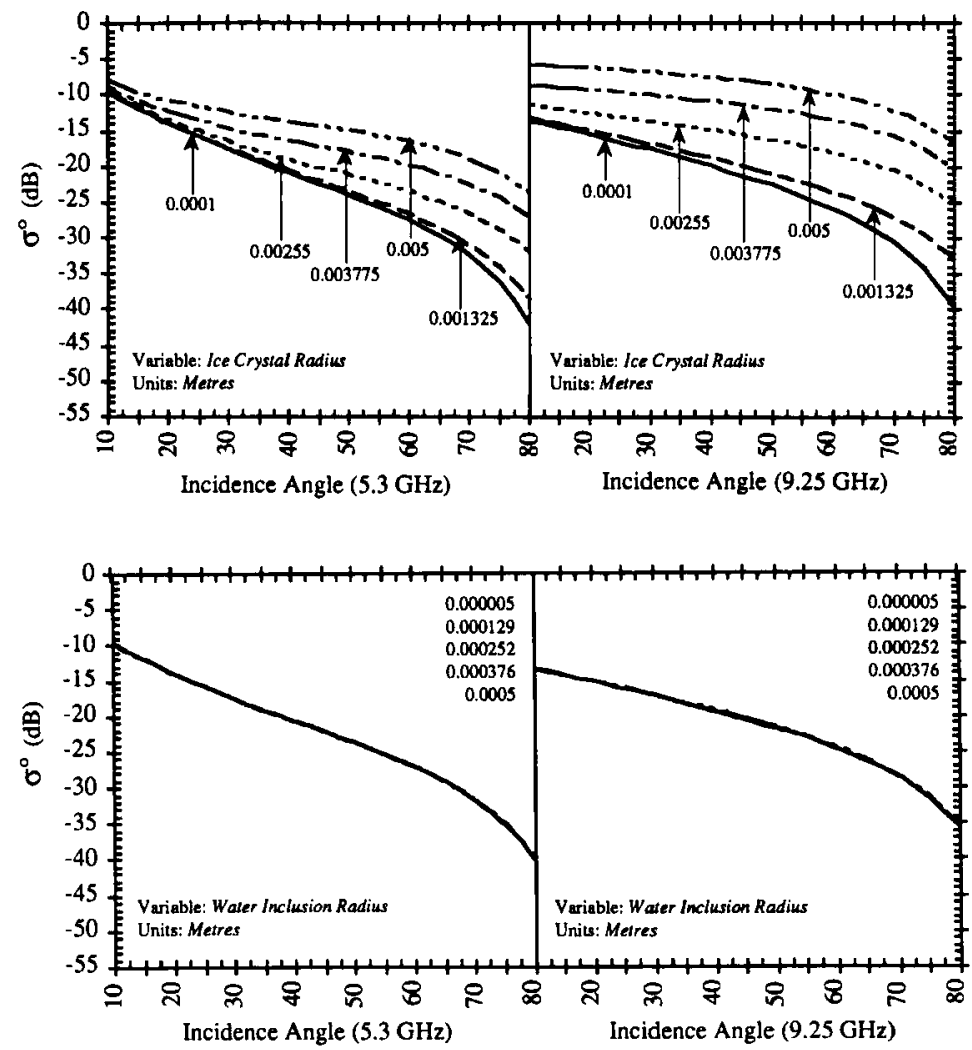

Fig. 23. Sensitivities of the snow crystal radius $\left(\mathbf{R}_{i}\right)$ variable at 5.3 and $9.25 \mathrm{GHz}$ frequencies over the incidence angle range 10 to $80 \mathrm{deg}$ rees. Initialization conditions of concomitant variables are specified in Table 2.

Fig. 24. Sensitivities of the water inclusion radius $\left(R_{i}\right)$ variable at 5.3 and $9.25 \mathrm{GHz}$ frequencies over the incidence angle range 10 to $80 \mathrm{deg}$ rees. Initialization conditions of concomitant variables are specified in Table 2.

tested. There is a minimum difference in $\sigma^{0}$ of $10 \mathrm{~dB}$ at $10^{\circ}$ and a maximum of $25 \mathrm{~dB}$ at $80^{\circ}$ incidence (Fig. 23). The larger separation at the shallower incidence angles between $\mathrm{C}$ and $\mathrm{X}$ band the fact that the scattering coefficients for the water inclusions $\left(\sigma_{\mathrm{bw}}\right)$ were between 5 and 7 orders of magnitude smaller than the same coefficient for the ice crystal radii $\left(\sigma_{\mathrm{bi}}\right)$. This resulted 
in a much smaller volume scattering coefficient $\left(\sigma_{v}\right)$ and therefore a smaller volume scattering cross section $\left(\sigma_{v}^{0}\right)$.

These sensitivity analyses have illustrated the relative importance of a set of geophysical variables in specification of $\sigma^{0}$. The results are contingent upon the correct implementation of the electromagnetic (EM) interaction physics within the surface and volume scattering models used here. As a forward model, the implementation of easily observable geophysical properties within the scattering models is an important prerequisite to understanding the mechanics of the interaction process, for development of invertable models, and for defining constraints within which synthetic aperture radar (SAR) data may be interpreted. Although the models used here have met with considerable success in measurement of $\sigma^{0}$ over snow-covered sea ice, the results are considered significant as a relative, rather than absolute, measure of the seasonal evolution of $\boldsymbol{\sigma}^{0}$.

\section{Conclusions}

In this paper we have introduced the concept of an integrated microwave scattering model which is appropriate for modeling the total relative scattering cross section $\left(\sigma^{0}\right)$ from a variety of snowcovered sea ice volumes. In previous work (Livingstone \& Drinkwater 1991) this model correctly approximated the total scattering cross sections observed for conditions similar to those sampled during SIMMS' 90 and ' 91 . Although the model accounts for only first order heterogeneity of the volume, it would appear to reproduce the approximate magnitude and range of $\sigma^{0}$ over the seasonally variable snow-covered sea ice volume.

The sensitivity analyses were begun using dielectric mixture models. Results of these models were used to illustrate the concept that the dielectric properties of snow and sea ice are highly dynamic and, as such, are critical in understanding the seasonal scattering mechanisms. Winter sea ice dielectric properties were modeled and the 3 phase combinations of ice crystals, air pockets and brine were shown to have considerable influence on the permittivity $\left(\varepsilon^{\prime}\right)$ and loss $\left(\varepsilon^{\prime \prime}\right)$ of sea ice. The influence of a snow cover on dielectric properties of Winter season sea ice was explored by using a one-dimensional thermodynamic model forwarded by Nakawo \& Sinha (1981). The impact of a small snow thickness over sea ice was shown to have a significant impact on the dielectric properties of first-year sea ice.

The dielectric properties of a snow cover were explored using a series of dry and wet snow semiempirical models. The seasonal transition period from the Winter SAR scattering season to Early Melt was shown to signal the transition in dielectric properties which caused the snow volume to become a major factor in the microwave scattering process. The effect of water volume within the snow cover was shown to be snow density and microwave frequency dependent on both $\varepsilon^{\prime}$ and $\varepsilon^{\prime \prime}$. In a relative sense the sensitivity of $\varepsilon^{\prime \prime}$ was larger than for $\varepsilon^{\prime}$ for a given set of snow density, water volume and microwave frequency parameters.

The effect of the thermal insulation of a snow cover on sea ice was shown to be significant for both $\varepsilon^{\prime}$ and $\varepsilon^{\prime \prime}$. Higher atmospheric temperatures caused proportionally higher changes in the dielectric properties of the sea ice at the base of the snow pack. At the conclusion of this subsection it was shown that the microwave penetration depth was a function of the increase in $\varepsilon^{\prime}$ and $\varepsilon^{\prime \prime}$. This led to the conclusion that microwave scattering from a snow-covered sea ice volume would consist primarily of snow surface and snow volume contributions to $\sigma^{0}$. Each of which would result, to varying degrees, from changes in the volume dielectric and scattering cross sections of the material within the background dielectric.

The next set of sensitivity analyses were computed for the total relative scattering cross section $\left(\sigma^{0}\right)$ using a range of sensor, sensor-earth geometry, and geophysical properties. The range and magnitude of these variables were selected to approximate the conditions observed during SIMMS' 90 and SIMMS' 91 for the transition from Winter to Advanced Melt.

In the Winter season the surface roughness terms $\left(\sigma_{\mathrm{h}}\right.$ and $\left.\mathrm{L}\right)$ were shown to have a significant impact on $\sigma^{0}$ when the ice surface was the primary scattering mechanism. Small changes in the RMS height $\left(\sigma_{\mathrm{h}}\right)$ and correlation length (L) created dramatic changes in $\sigma^{0}$. Once the snow pack began to warm and water was available in a liquid or vapour phase, the ice surface became masked because of the decrease in microwave penetration depths. This masking of the ice surface was observed in uncalibrated SAR data acquired during SIMMS'90 (Barber et al. 1992b) within the Melt Onset season.

During the transitional seasons (Early Melt, 
Melt Onset and Advanced Melt), it was concluded that the snow water volume $\left(W_{v}\right)$ variable was an important parameter in specifying $\sigma^{0}$, both from its impact on $\sigma_{v}^{0}$ and due to its control over the dielectric mismatch created at the air/snow interface. Both snow density $\left(\rho_{\mathrm{s}}\right)$ and the snow crystal radius $\left(\mathbf{R}_{i}\right)$ were shown to play a significant role in specifying $\sigma^{0}$. As $\rho_{\mathrm{s}}$ and $\mathrm{R}_{\mathrm{i}}$ increased so $\operatorname{did} \sigma^{0}$. Although the water inclusion radius $\left(\mathbf{R}_{w}\right)$ variable did impact $\sigma_{\mathrm{v}}^{0}$, the effect was masked by the much larger increase in the $R_{i}$ term. The significance of snow depth $\left(\mathrm{D}_{\mathrm{s}}\right)$ on $\sigma^{0}$ was shown to be a subtle relationship between the frequency of the incident radiation and the incidence angle. It appeared from these analyses that a combined 5.3 and $9.25 \mathrm{GHz}$ frequency could be used to obtain $\mathrm{D}_{\mathrm{s}}$ from $\sigma^{0}$.

In summary, it was shown that as $\mathbf{W}_{\mathrm{v}}$ increased there was a shift in significance towards the $\sigma_{v}^{0}$ term of $\sigma^{0}$ from $\sigma_{\mathrm{si}}^{0}$ (ice surface roughness). Once the $W_{v}$ term, in combination with $R_{i}$, and $\rho_{s}$, were large enough to restrict the penetration depth to $\mathrm{mm}$ range then $\sigma_{\mathrm{ss}}^{0}$ began to dominate over $\sigma_{\mathrm{v}}^{0}$ in the specification of $\sigma^{0}$. This meant the $\sigma_{\mathrm{h}}$ and $\mathrm{L}$ of the snow surface became the important variables in defining the magnitude and range of $\sigma^{0}$.

Acknowledgements. - Many individuals bring their individual expertise to bear within the SIMMS experiment. Thanks to: T. Papakyriakou, R. De Abreu, S. Redan, D. Flett, M. Shokr, M. Manore, S. Paterson, J.-C. Deguise, B. Ramsay and K. Lamothe. The SIMMS program is undertaken with support from a variety of agencies including a Centre of Excellence grant from the Province of Ontario and an NSERC (Natural Sciences and Engincering Research Council) Operating Grant, both to $\mathrm{E}$. LeDrew. M. Drinkwater provided invaluable assistance in the implementation of the microwave scattering models used here. We thank him for his guidance and encouragement throughout this project.

\section{References}

Assur, A. 1960: Composition of sea ice and its tensile strength, SIPRE Research Report 44. $86 \mathrm{pp}$.

Barber, D. G., Johnson, D. \& LeDrew, E. F. 1991: Measuring climatic state variables from SAR images of sea ice: The SIMMS SAR Validation Site in Lancaster Sound. Arctic. 44, 101-121.

Barber, D. G. , Flett, D. G., De Abreu, R. A. \& LeDrew, E. F. 1992a: Spatial and temporal variations in sea ice geophysical properties and microwave remote sensing observations: The SIMMS'90 experiment. Arctic. 45(3), 233-251.

Barber, D. G., Le Drew, E. F., Shokr, M. \& Falkingham, J. 1992b: Seasonal and diurnal variations in SAR signatures of sea ice. IEEE Trans. Geosci. Remote Sens. 30(3), 638-642.
Colbeck, S. C. 1981: The geometry and permittivity of snow at high frequencies. J. Appl. Phys. 53(6), 4495-4500

Crocker, G. B. 1984: The physical properties of snowcover on sea ice in the Central High Arctic. Department of Geography, McGill University, M.S. thesis. 180 pp.

Drinkwater, M. R. 1989: LIMEX'/87 Ice surface characteristics: implications for C-band SAR backscatter signatures. IEEE Trans. Geosci. Remote Sens. 27(5), 501-513

Drinkwater, M. R. \& Crocker, G. B. 1988: Modeling changes in the dielectric and scattering properties of young snowcovered sea ice at $\mathrm{GHz}$ frequencies. J. Glaciol. 34(118), 274282.

Frankenstein, G. \& Garner, R. 1967: Equations for determining the brine volume of sea ice from -0.5 to -22.9 degrees $C$. J. Glaciol. 6(48), 943-944.

Johansson, R. \& Askne, J. 1987: Modeling of radar backscattering from low-salinity ice with ice ridges. Internat. $J$. Remote Sens. 8(11), 1667-1677.

Hoekstra, P. \& Cappillino, P. 1971: Dielectric properties of sea and sodium chloride ice at UHF and microwave frequencies. J. Geophys. Res. 76, 4922-4931.

Kim, Y. S. 1984: Theoretical and experimental study of radar backscatter from sea ice. Ph.D. dissertation, University of Kansas. $168 \mathrm{pp}$.

Kim, Y. S., Onstott, R. G. \& Moore, R. K. 1984: The effect of a snow cover on microwave backscatter from sea ice. IEEE J. Oceanic Engin. OE-9(5), 383-388.

Kim, Y. S., Moore, R. K., Onstott, R. G. \& Gogennini, S. 1985: Towards identification of optimum radar parameters for sea ice monitoring. J. Glaciol. 3I(109), 214-219.

Livingstone, C. E., Onstott, R. G., Arsenault, L. D., Gray, L. \& Singh, K. P. 1987: Microwave sea-ice signatures near the onset of melt. IEEE Trans. Geosci. Remote Sens. GE-25(2), 174-187.

Livingstone, C. E. 1989: Combined active/passive microwave classification of sea ice. IGARS 89. July 10-14, Vancouver Canada l, 376-380.

Livingstone, C. E. \& Drinkwater, M. R. 1991: Springtime C-band SAR backscatter signatures of Labrador Sea marginal ice: measurements versus modeling predictions. IEEE Trans. Geosci Remote Sens. 29(I), $29-41$.

Matzler, C. 1987: Applications of the interaction of microwaves with the natural snow cover. Remote Sens. Rev. 2, 259-387.

Nakawo, M. \& Sinha, N. K. 1981: Growth rate and salinity profile of first-year sea ice in the High Arctic. J. Glaciol. 27(96), 315-330.

Tiuri, M. E., Sihvola, A. H., Nyfors, E. G. \& Hallikainen, M. T. 1984: The complex dielectric constant of snow at microwave frequencies. IEEE J. Oceanic Engin. $O E-9$ (5), 377382

Ulaby, F. T., Moore, R. K. \& Fung, A. K. 1986: Microwave remote sensing: active and passive. Vol. III. Addison-Wesley Publishing Company, Massachusetts.

Vant, M. R. . Ramscier, R. O. \& Makios, V. 1978: The complexdielectric constant of sea ice at frequencies in the range 0.1 to $40 \mathrm{GHz}$. J. Appl. Phys. 49(3), 1264-1280.

Winebrenner, D. P., Tsang. L., Wen, B. \& West, R. 1989: Sea ice characterizations measurements needed for testing of microwave remote sensing models. IEEE J. Oceanic Eng. I4(2), 149-158. 